\title{
Features of near and far SOL heat fluxes on the Wendelstein 7-X inboard limiters
}

\author{
H. Niemann ${ }^{1,2}$, M. W. Jakubowski ${ }^{1,3}$, F. Effenberg ${ }^{4,5}$, S. A. \\ Bozhenkov $^{1}$, B. Cannas ${ }^{6}$, D. Carralero ${ }^{7}$, A. Langenberg ${ }^{1}$, \\ F.Pisano $^{6}$, K. Rahbarnia ${ }^{1}$, L. Rudischhauser ${ }^{1}$, T. Stange $^{1}$, F. \\ Warmer $^{1}$, G. A. Wurden ${ }^{8}$ and the W7-X Team ${ }^{1}$ \\ 1 Max-Planck-Institut für Plasmaphysik, Wendelsteinstr. 1, 17491 Greifswald, \\ Germany \\ 2 Insitut für Physik, Universität Greifswald, Greifswald, Germany \\ 3 University of Szczecin, Szczecin, Poland \\ 4 Department of Engineering Physics, University of Wisconsin, Madison, WI 53706, \\ USA \\ 5 Princeton Plasma Physics Laboratory, Princeton University, Princeton, New Jersey \\ 08543, USA \\ 6 University of Cagliari, Cagliari, Italy \\ 7 CIEMAT-Laboratorio Nacional de Fusin, Avda. Complutense 40, 28040 Madrid, \\ Spain \\ 8 Los Alamos National Laboratory, PO Box 1663, Los Alamos, NM 87545, USA \\ E-mail: Holger.Niemann@ipp.mpg.de
}

\begin{abstract}
The power fall-off length is used as a characteristic dimension to describe the power exhaust in the scrape-off layer in magnetic confinement fusion devices. Measurements from the limiter campaign of the stellarator Wendelstein 7-X with inboard limiters are presented with the first-time characterization of the limiter heat loads. Two fall-off regimes are found with a narrow near SOL with power fall-off length in millimeters and a wider far SOL with fall-off lengths of several centimeters. An attempt is made to describe both regimes with a scaling law for plasma with different heating powers and densities. The results confirm the major geometry effects of the connection length on the heat transport predicted by $3 \mathrm{D}$ modeling.
\end{abstract}

Submitted to: Nucl. Fusion

Keywords: W7-X, stellarator, strike line, heat loads, limiter, fall-off length, scrape-off layer, plasma surface interaction 


\section{Introduction}

In order to ensure safe operation of present and future fusion devices, proper handling of the power exhaust needs to be addressed. In tokamaks, a poloidal divertor is widely used because it separates the plasma material interaction zone from the central plasma.

5 Although this concept is well established, different design concepts for the plasma-facing components as well as magnetic field geometry are studied in tokamaks and stellarators to find alternative ways for the heat exhaust. A narrow region at the plasma edge, where the power leaves the confined plasma region through the last closed flux surface and is deposited along open magnetic flux tubes to the plasma-facing components, is called scrape-off layer (SOL). The radial fall-off of the power flux in SOL results from competition between parallel and perpendicular heat transport. Due to the significant difference between parallel and perpendicular heat transport is the typical fall-off length in tokamaks very narrow. This is of particular interest for next step devices, e.g., ITER where a significant amount of power $\left(\mathrm{P}_{S O L}=80-130 \mathrm{MW}\right.$ for divertor operation in D-T [1], $\mathrm{P}_{S O L}=3-5 \mathrm{MW}$ [2] for limiter operation) needs to leave the plasma. Therefore many studies of power fall-off length have been performed on different devices.

It is widely acknowledged that turbulence can play a role in the perpendicular transport. Nevertheless, the shape of the radial profile of the parallel power flux is usually described with the help of an exponential decay function

$$
q_{\|}=q_{0} \exp \left(-\frac{\left(r-r_{L C F S}\right)}{\lambda_{q}}\right)
$$

with $q_{0}$ the parallel heat flux at the LCFS and $\mathrm{r}_{L C F S}$ the radius of the LCFS, a functional form resulting from a diffusive ansatz for the perpendicular transport.

However, many tokamaks reported that in a case of plasmas limited by an inboard limiter, a second, narrow fall-off length has been found very near to LCFS [3, 4, 5, 6]. In the far SOL, the power fall-off length is reported to be of the order of 1-2 centimeters, while in the near SOL it is only a few millimeters. The equation 1 needs to incorporate both SOLs and takes the following form

$$
q_{\|}=q_{n} \exp \left(-\frac{\left(r-r_{L C F S}\right)}{\lambda_{q n}}\right)+q_{f} \exp \left(-\frac{\left(r-r_{L C F S}\right)}{\lambda_{q f}}\right)
$$

with $\lambda_{q n}$ the narrow fall-off length in the near SOL, $\lambda_{q f}$ the fall-off length of the far SOL and $\mathrm{q}_{n}, \mathrm{q}_{f}$ the contributions of both regions to the parallel flux at the LCFS.

The near SOL was measured first at JET[3] with IR thermography and Langmuir probes. As a result, multi-machine studies were triggered to measure the near and far SOL on the inner and outer limiters.

The physics mechanisms leading to the formation of the near SOL is not yet fully understood. At JET a hypothesis was formed that the enhanced inner wall loads may result from funneling effect (i.e., additional power deposition due to cross-field transport) or possibly as a result of the diffusive attraction of the heat flux at the limiter ridge. However, the assumptions in both models are unlikely to fulfill the experimental conditions 
in JET [3]. Results from TCV [4, 5] and COMPASS 6, 7] showed that non-ambipolar currents correlate with the power entering the near SOL, but their presence alone is not sufficient to explain the enhancement in the heat deposition close to the limiter. The nonambipolar current model is only capable of explaining 2\% (ion side) to $45 \%$ (electron side) of the increase of the heat-flux in the near SOL in COMPASS [7]. Another explanation for the formation of the near SOL is drift effects. It has been shown, that the heuristic drift (HD) model [8], which meant to describe the power fall-off length in tokamak divertor H-mode, fit well to the observations of the near SOL in inboard limited plasmas [6, 7]. The measurements in TCV show that the near SOL feature is suppressed for low plasma currents or high densities and the scaling in TCV can be described by the HD model if it is multiplying with the normalized Spitzer resistivity [5]. Furthermore, it was shown in TCV, that the near SOL feature also appears on the outboard limited plasmas, but with a much wider power fall-off length [9]. Consistency between the measurements, nonlinear turbulence simulations, and an analytical model taking sheared ExB flow as an explanation for the near SOL feature have been reported by TCV [9].

The scaling of the far SOL power fall-off length has been investigated for a long 45 time on many machines. Typically empirical scaling laws in the form of power laws, have been applied to a database, which contains measurements of 11 different tokamaks[10]. A theoretical description of the formation of the far SOL fall-off length, including turbulence with a quasi-linear model has been derived and shown to reach a similar regression value as the empirical models [11].

For ITER, a good estimation of the scrape-off layer behavior and width is needed to find a proper design to handle the large amount of energy leaving the plasma. The plasma start is favored to be attached mainly to the inner limiters for several reasons [2]. A single exponential fall-off length was assumed in the initial design of the ITER first wall [12, 13]. This assumption was driven by measurements with Langmuir probes in JET, ${ }_{55}$ Tore Supra, and DIII-D [2]. The additional narrow channel near the LCFS would raise the heat flux onto the limiter at the apex by a factor of 4 above the expected values. Therefore a design of the ITER first wall[2] and for the EU DEMO [14] has been changed in order to accommodate increased heat flux due to near SOL.

In this paper, the results of the thermographic observation of inner limiter and the deduced power fall-off length in the first operation phase of Wendelstein 7-X(W7-X) are presented. Up to now, there were no studies of SOL parameters in stellarators apart of LHD [15, 16] and W7-AS [17]. As W7-X in the initial phase operated with five inboard limiters [18, 19], it gave us the possibility to look into the issue of near and far SOL in a large stellarator. The paper is structured in the following way; section 2 introduces $\mathrm{W} 7-\mathrm{X}$ and section 3 describes the evaluation of the data from the infrared system in more details. Afterward, in section 4, measurements, and the method to calculate the power fall-off length is described. Section 5 shows the main results and the scaling of the falloff length with different plasma parameters. In section 6 the results from section 5 are discussed and finally concluded in section 7 . 


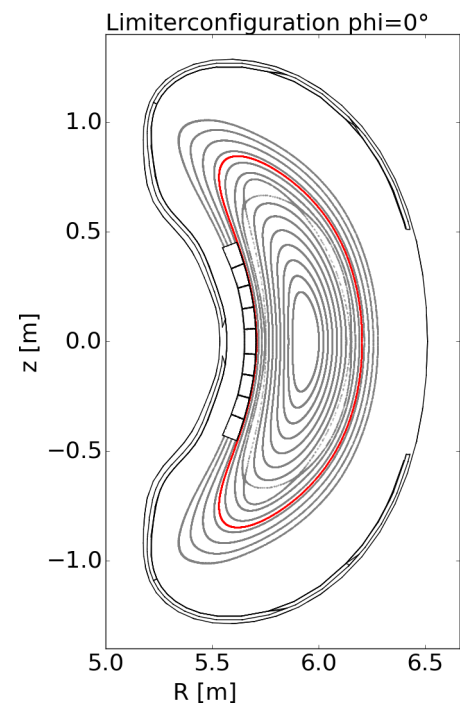

(a) Poincare

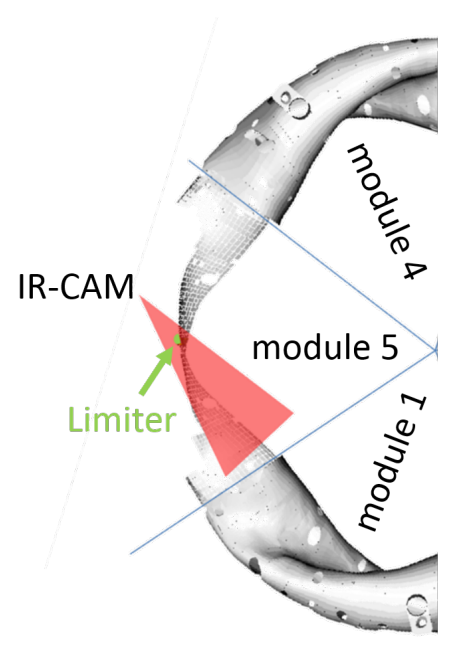

(b) Top-down view

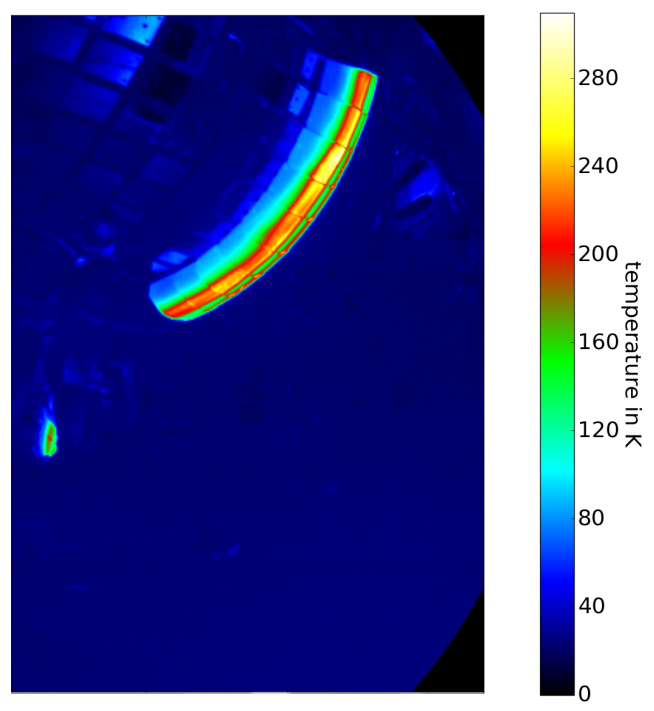

(c) IR view

Figure 1. (a) Poincare Plot for vacuum field and ideal coils of the limiter configuration at the bean-shape plane. The LCFS is shown in red, and the nine limiters tiles are visible at the inner side of the machine. (b) Top-down view on the CAD model of the plasma vessel of Wendelstein $7-\mathrm{X}$. The machine is structured into five similar modules corresponding to the five-fold symmetry. The sightlines of the radial viewing FLIR and the toroidal viewing DIAS IR camera system are shown in red. The Limiters are shown in green. (c) IR image from the DIAS camera system. The inboard side of W7-X in module 5 with temperature pattern on limiter 5 is visible. Additionally, a reflection on the divertor mounting structure can be seen at the left side.

\section{Experimental set-up}

Wendelstein 7-X (W7-X), an advanced stellarator with five-fold symmetry, started its first plasma operation phase (OP 1.1) in December 2015. The five-fold symmetry is represented in the vessel structure with five similar modules (later named module 1 to 5 ). The inner wall (IW) of the plasma vessel had large surface areas of exposed tiles. Each module was equipped with an uncooled poloidal limiter [19] to protect these areas from plasma contact. The five limiters were located on the inboard, high field side (HFS) of the plasma vessel [18] (figure 1(b)]. Each limiter consisting of 9 fine graphite tiles, is specially shaped to be parallel to the magnetic field in the bean-shape plane and designed to handle heat fluxes up to $10 \mathrm{MW} / \mathrm{m}^{2}$ [20]. The magnetic field configuration for the limiter phase has been chosen to avoid stochastic regions and large magnetic islands in the scrape-off layer (SOL) (see figure 1(a)). The large islands, which are used in the divertor configurations are pushed inward, into the confined region, to avoid shortcuts in the heat and particle transport towards the wall. This magnetic field assures that the limiters efficiently intercept $>99 \%$ of the convective plasma heat load at the plasma edge. In order to protect parts of the plasma vessel, the total injected power per discharge was administratively limited to $4 \mathrm{MJ}$ for machine safety. In OP1.1 electron cyclotron resonance heating $(\mathrm{ECRH})$ was used with power between $4 \mathrm{MW}$ (for up to $1 \mathrm{~s}$ ) and $0.6 \mathrm{MW}$ 
( for up to $6 \mathrm{~s}$ ). For almost all discharges in OP1.1, the toroidal current was very low $\left(I_{\text {tor }} \leq 2 \mathrm{kA}\right.$, see also table 1) and the Shafranov shift was negligible. In such a case, a 90 so-called vacuum approach with no plasma response included delivers a valid model for the description of magnetic edge topology. Such an approach will be used throughout the rest of the paper.

In the first campaign, a basic IR observations system with nine near IR (NIR), one mid-wavelength IR (MWIR) and one long-wavelength IR (LWIR) camera were used to measure the surface temperature of the inboard limiters [21]. Figure 1(b)] shows a topdown view onto a simplified CAD model of the W7-X inner vessel. The position of the LWIR camera and its view cone is shown in red. The limiters are highlighted in green. The LWIR system contains a modified micro-bolometer camera $(8-14 \mu \mathrm{m}, 50 \mathrm{~Hz}, 640 x 480$ Pixel) which can operate inside a high magnetic field [22, 23]. The camera was located inside an immersion tube, which was inserted into W7-X between the coils. The camera was observing the left side of all nine tiles of the limiter in module 5 [24](figure 1(c). The other half of the limiter showed similar load pattern following the W7-X symmetry.

Since the data of the NIR cameras suffered from the plasma emission [21] it is excluded from the further analysis. The other MWIR system is also excluded from the analysis due to having only a partial view of the limiter. Because of this, the rest of the paper will concentrate on the measurement of the LWIR camera.

\section{Infrared measurements}

\subsection{Lens distortions and spatial calibration}

The immersion tube set-up [25] was planned to observe the limiters in the first operation phase and the inertially cooled divertors in the upcoming operation phase [23, 21]. Therefore, the LWIR IR camera was equipped with a special wide-angle lens which allows a field of view of $116^{\circ} \times 82^{\circ}$ [22]. Together with the large field of view, the wide-angle lens also adds strong radial optical distortions into the image. Multiple views of a checkerboard have been used to estimate the intrinsic lens parameter matrix and to correct the strong radial lens distortion for the LWIR camera system. [26]. These parameters are used to map the infrared images onto a simplified CAD Model of the plasma-facing components observed by the camera (e.g., limiter, wall panels, vacuum vessel) [26]. From the spatial calibration, a map file, connecting each pixel to a 3D-coordinate inside the machine, is created. This information is then used to determine the real space distance between two pixels.

\subsection{Emissivity corrections}

In order to properly interpret photon flux measured by an IR camera as surface temperature, it is important to know precisely the emissivity of this surface. Throughout the campaign, a slow evolution of the physical properties of the limiter surface has been 

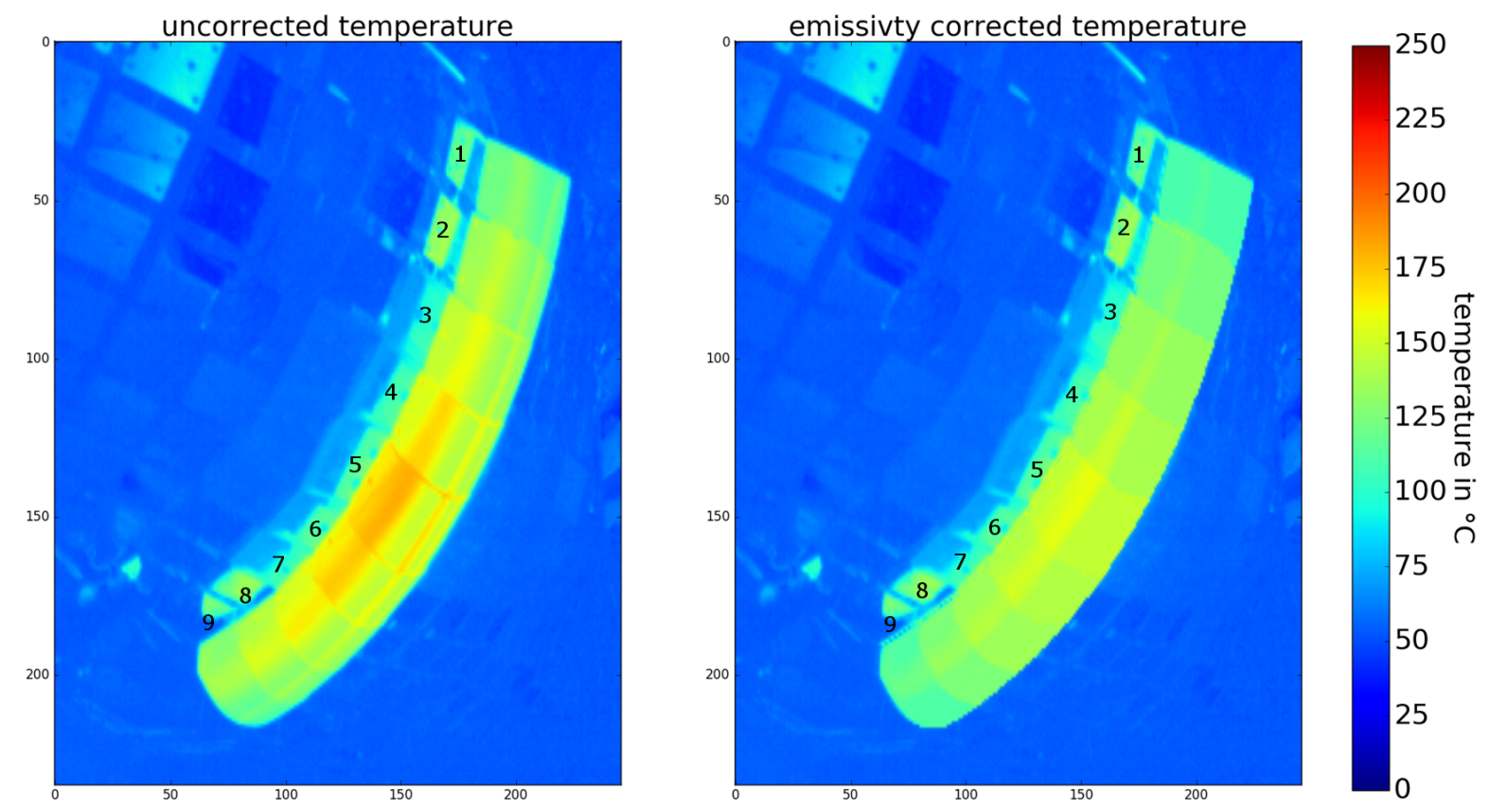

Figure 2. The left graph shows an uncorrected infrared image measured shortly before the discharge, the right one shows an emissivity corrected image. In the left image, four different regions can be seen: a deposition zone at the edge of tiles 4,5,6 with a higher emissivity, adjacent the erosion area with constant emissivity, near the center the re-deposition zone with higher emissivity. In the very center of the limiter the smoothed region with unchanged emissivity [27, 28,

detected. The post-campaign analyses show that the surface changes can be structured into four regions: an outer deposition zone with thin layers of $200 \mathrm{~nm}$ to $1 \mu \mathrm{m}$, a net erosion zone at the strike-line, a prompt re-deposition zone in the strike-line near the center and a smoothed watershed [27]. These changes of the physical properties of the material resulted in local modification of the limiter surface emissivity. The areas of modified emissivity form strike line like patterns which are running poloidally along the limiter. A method for an emissivity correction for all analyzed discharges was developed, based on the emissivity measurements in [28]. An example is shown in figure 2. The left and right graph respectively show thermal images of the limiter without and with emissivity correction, taken shortly before the discharge.

The emissivity correction is applied separately to each analyzed discharge, to take all surface changes from experiment to experiment into account. The assumption is made that each tile of the limiter is in thermal equilibrium shortly before the discharge. As a result, the surface temperature within each tile should be similar. This assumption implies that the surface temperature variation in the left image of figure 2 is caused by emissivity variations of the surface. Each pixel of a tile is compared to an area within the same tile with known emissivity. The emissivity of each pixel is adjusted until the apparent temperature reaches a similar value or until the emissivity reaches the value of one. The reference area is taken from the middle part of the limiter, where the emissivity 


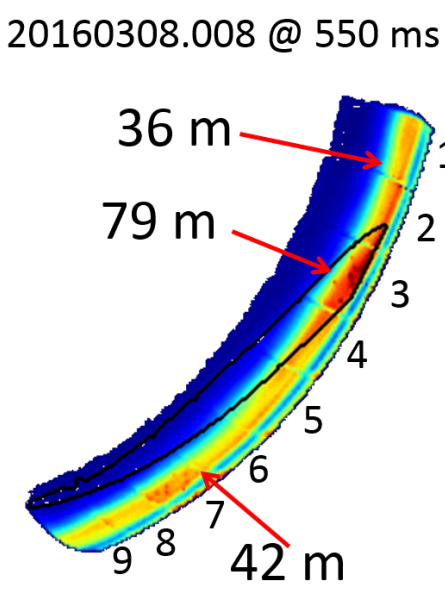

(a)
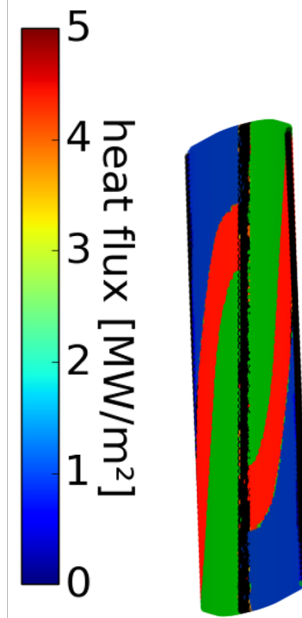

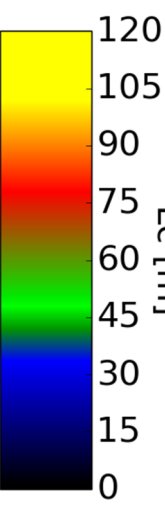

(b)

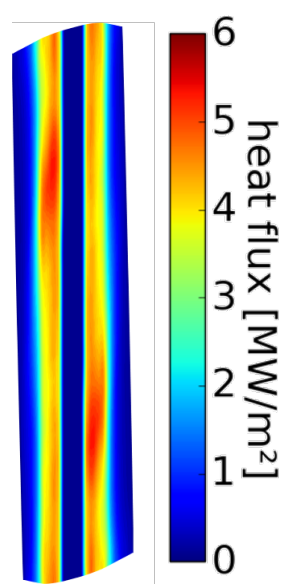

(c)

Figure 3. (a) View of the DIAS camera system onto the left side of limiter 5. All nine graphite tiles are visible. The calculated heat flux for a $4 \mathrm{MW}$ discharge is color-coded. The three different flux tube regions are indicated with red arrows and a contour plot for the $79 \mathrm{~m}$ long flux tube. The dark red spots on tile 3 and 7 are artificial heat flux, caused by the embedded Langmuir probes (b) Pattern of the connection length on the limiter surface from FLT simulation (c) Limiter load from an EMC3-EIRENE Simulation with $\mathrm{P}=3.2 \mathrm{MW}, \mathrm{n}_{e}=8 \mathrm{e} 18 \mathrm{~m}^{3}, \mathrm{D}=1.5 \mathrm{~m}^{2} / \mathrm{s}, 25 \%$ energy loss by carbon radiation

was unchanged during the campaign and was equal to 0.82 .

\subsection{Heat flux calculation}

After the corrections are applied, each limiter is divided into 450 1D line profiles to cover the surface of all nine tiles. The heat fluxes on the target surfaces are calculated by applying a standard numerical solution of the two-dimensional heat diffusion equations to the evolution of the surface temperature on the investigated area with the THEODOR code [29, 30]. The code numerically solves the equations taking into account temperaturedependent material parameters. The two dimensions used here are the depth of the limiter (ignoring its curvature) and the coordinate along the temperature profiles. The gaps between the profiles and the missing pixels are interpolated afterwards to get a full heat flux pattern of the limiter. An example of a heat flux pattern mapped back into the $2 \mathrm{D}$ image is shown in figure $3(\mathrm{a})$.

\section{Limiter power loads}

As presented in Fig. 3 the power loads on the limiter have a shape of two heat stripes, which are running along the length of the limiter separated by the watershed area. Fieldline tracing (3(b) and EMC3-EIRENE simulations (3(c) [31]) indicate that the W7-X SOL in OP1.1 consisted of three different helical magnetic flux bundles (indicated as the blue, green and red shape in $3(\mathrm{~b})$ with limiter-to-limiter connection length of $36 \mathrm{~m}, 43$ 
$\mathrm{m}$ and $79 \mathrm{~m}$. These three flux bundles yield heterogeneous power deposition patterns within each of two heat stripes. The maximum of the heat load is located in the region of the flux tube with a connection length of $79 \mathrm{~m} \mathrm{[31].} \mathrm{The} \mathrm{heat} \mathrm{transport} \mathrm{channel} \mathrm{along}$ the flux tubes of different connection lengths can be identified in the power load distributions measured by both cameras [24, 28. Figure 3(a) shows one example of a power load calculated from the thermographic observation with the LWIR camera. In this graph, the left side of limiter 5 and the left strike-line running down the limiter are shown. A contour plot of the magnetic footprint is overlaid on this figure to indicate the positions of the three flux bundles. Comparing the measured heat flux density with EMC3-EIRENE simulation results shows relatively good agreement, i.e., both measurements and modeling resolve three different heat flux channels in the scrape-off layer of limiter plasmas at W7-X.

From the calculated heat flux density $q_{\text {depo }}$ the parallel heat flux density $q_{\|}$is calculated using the following relation:

$$
q_{\text {depo }}=q_{\|} \sin (\alpha)
$$

The parameter $\alpha$ is the incident angle of the magnetic field to the limiter surface. For the presented measurements, the incident angle is calculated between the field vectors of the magnetic field lines intersecting the limiters and the normal vector of this surface. The field line tracer (FLT) from the W7-X web-service system [32] is used to calculate the magnetic field. It solves the Biot-Savart equation for a given coil and current set.

It has to be mentioned here that the plasma radiation, predominantly inside the LCFS [33] act mostly as an energy sink. The contribution of radiated power, deposited on the limiter and vessel wall, is in the order of 5 to $20 \mathrm{~kW} / \mathrm{m}^{2}$. This contribution is an order of magnitude lower than the typical error assumed for the deposited heat flux onto the limiter. A radiation layer is also formed in front of the limiter by eroded particles. Assuming the worst case that the radiation in the SOL is concentrated in this layer results in a maximum radiation contribution of up to $100 \mathrm{~kW} / \mathrm{m}^{2}$, which is still lower than the assumed error. However, given the actual distribution, a lower contribution is expected.

After the calculation of the parallel heat flux, the FLT is used to project the heat flux data from the limiter surface onto a plane in order to remove from the analysis effects of the limiter's curvature. Each of the heat flux data points is assigned to a radial coordinate, which is defined as a distance from the last closed flux surface ( $\left.r_{\text {eff,LCFS }}\right)$. In such a way $3 \mathrm{D}$ heat flux data is simplified to $1 \mathrm{D}$ radial profiles of the parallel heat flux $q_{\|}\left(r_{\text {eff }}-r_{\text {eff,LCFS }}\right)$. The effective radius is used to overcome the non-trivial 3D formed plasma shape of W7-X, which goes from a bean-shape plane into a triangular plane and back to a bean-shape plane. It is defined by field lines or by the flux on a magnetic surface:

$$
r_{e f f}=\int_{0}^{V} \frac{d V^{\prime}}{S\left(V^{\prime}\right)}
$$

With $\mathrm{V}$ as the volume of the flux tube and $\mathrm{S}(\mathrm{V})$ the surface of the magnetic surface. For the definition by field lines, used by the FLT, the effective radius is traced out by 


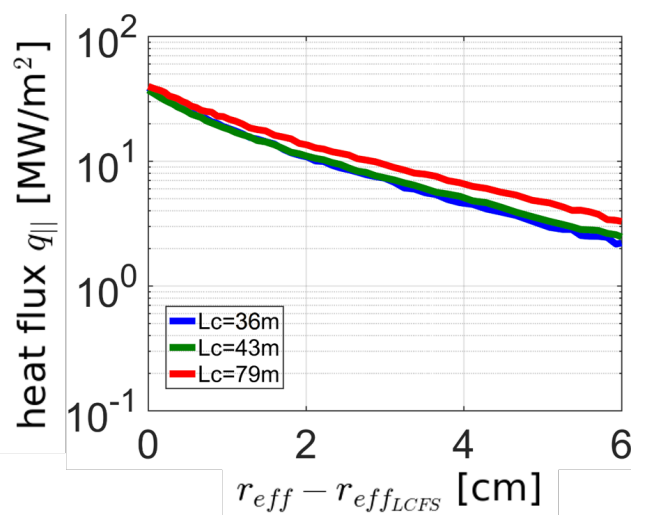

(a) EMC3-EIRENE

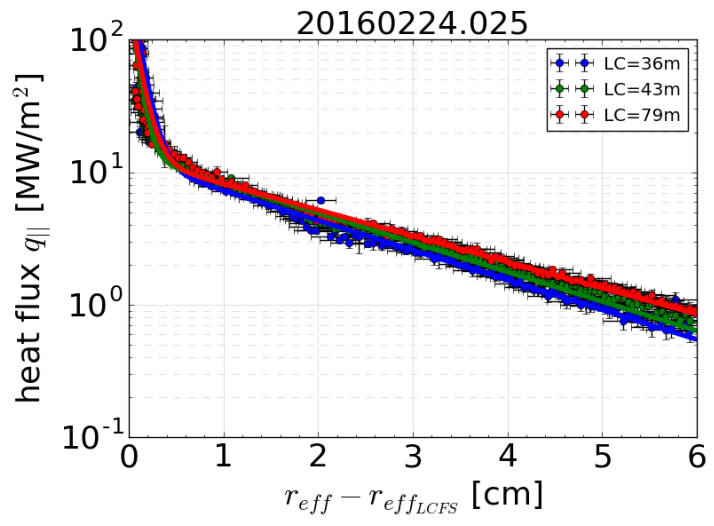

(b) IR

Figure 4. Profiles from the 3 different flux tubes for a) EMC3-EIRENE calculations with $\mathrm{P}=3.2 \mathrm{MW}, n_{e}=8 \mathrm{e} 18 \mathrm{~m}^{-3}, \mathrm{D}=1.5 \mathrm{~m}^{2} / \mathrm{s}, 25 \%$ energy loss by carbon radiation b) calculated from the IR measurements for the Program 20160224.025 with similar plasma parameters

following the field lines. For each field line, the geometric mean of the distance between points on the field line and the magnetic axis is calculated.

The results obtained for three flux tubes with different connection length are presented in Fig. 4. Both experimental data (right) and EMC3-EIRENE simulations (left) show increasing fall-off length for flux tubes with longer connection length (see figure 4(a) . The exact dependence will be discussed in Sec. 5.

In order to estimate the error of the parallel heat flux obtained with Eq. 3 an uncertainty of $0.2 \mathrm{MW} / \mathrm{m}^{2}$ for $q_{\| \text {depo }}$ is assumed based on measurements after the end of the plasma discharge. The remaining fluctuations around zero of the heat flux at the end of a program with no plasma contact are taken as a proxy for the error. An error for the calculated value of the incidence angle is obtained by calculating the magnetic field equilibrium with toroidal current between $0 \mathrm{kA}$ and $2 \mathrm{kA}$. The plasma current is simulated by another coil along the magnetic axis in the FLT. A one-pixel tolerance is used to calculate the spatial uncertainty for the presented data.

An exponential decay fit is applied to the radial profiles of the parallel heat flux:

$$
q_{\|}\left(r_{\mathrm{eff}}\right)=q_{\|, 0} \exp \left(-\frac{\left(r_{e f f}-r_{L C F S}\right)}{\lambda_{q}}\right)
$$

Where $r_{L C F S}$ represents the effective radius of the last closed flux surface, $q_{\|, 0}$ the heat flux density at the LCFS and $\lambda_{q}$ the power fall-off length for the parallel heat flux density. In figure 5 such a fit is represented as a dashed line. An exponential fit represents quite well the data only for $r_{\text {eff }}-r_{\text {eff,LCFS }} \geq 0.5 \mathrm{~cm}$. A double exponential fit function is required to accurately fit the parallel heat flux profile over the whole data range.

$$
q_{\|}\left(r_{\mathrm{eff}}\right)=q_{\|, n} \exp \left(-\frac{\left(r_{\mathrm{eff}}-r_{L C F S}\right)}{\lambda_{q n}}\right)+q_{\|, f} \exp \left(-\frac{\left(r_{\mathrm{eff}}-r_{L C F S}\right)}{\lambda_{q f}}\right)
$$




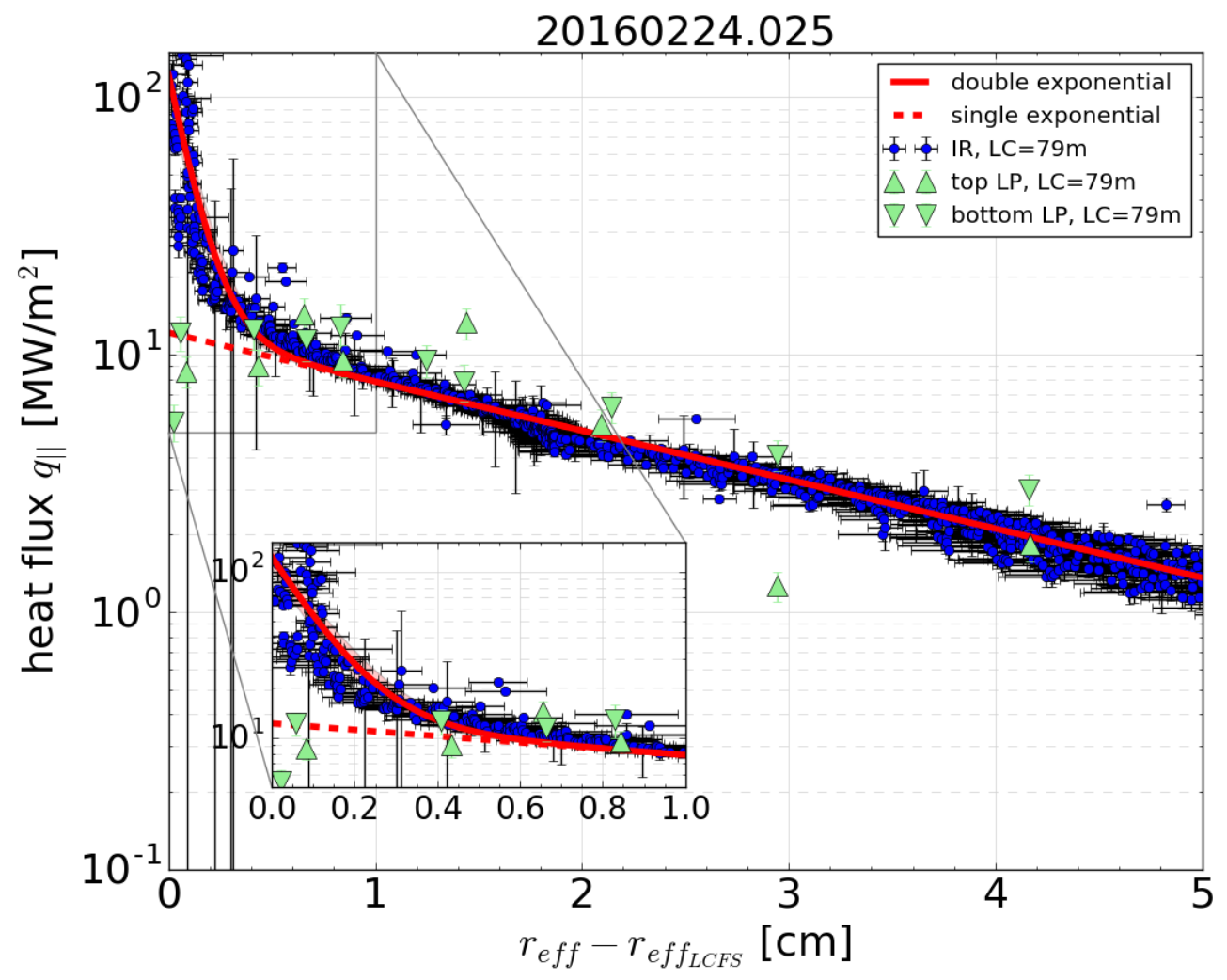

(a) parallel heat flux profile (semi-log)

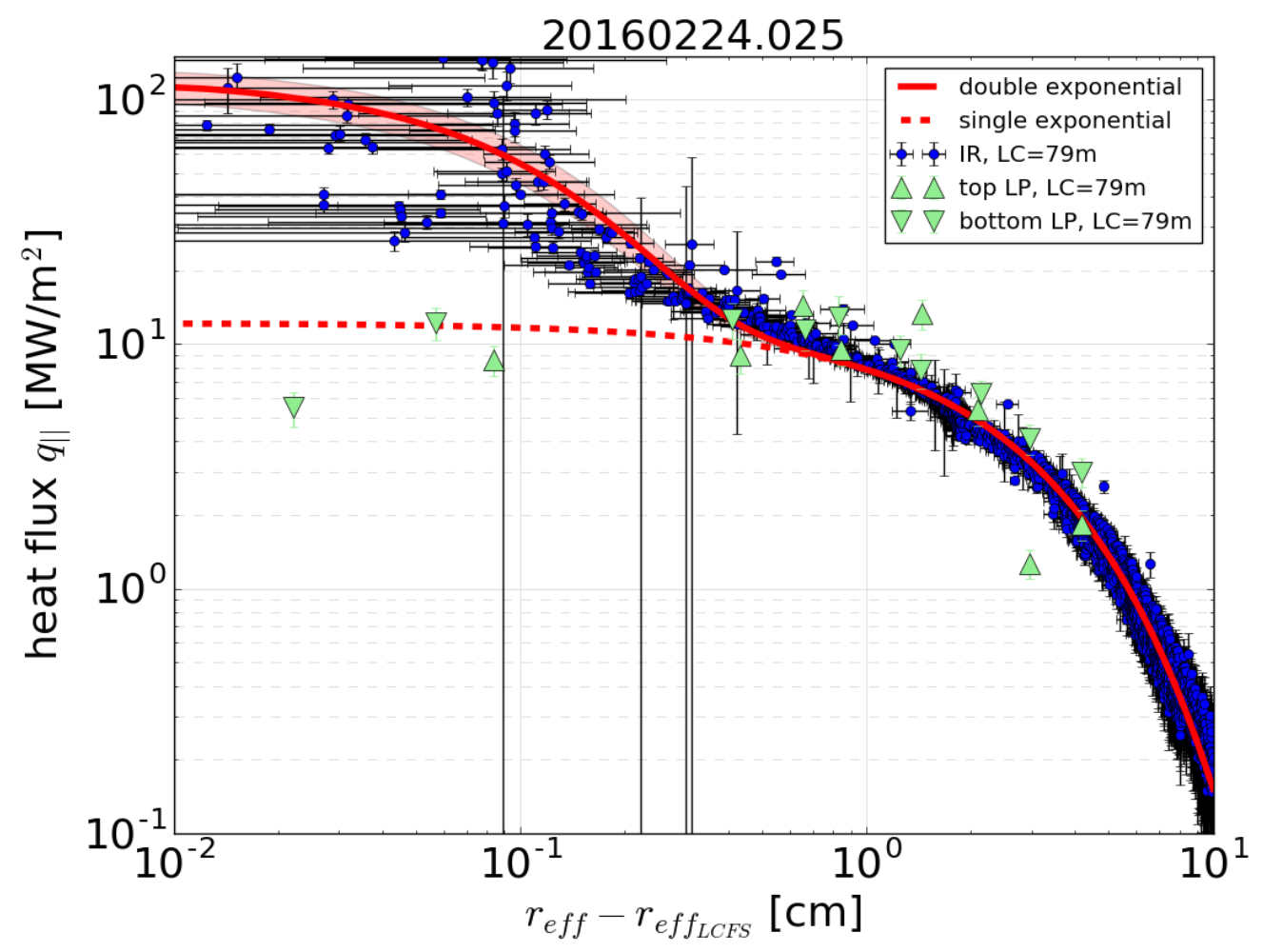

(b) parallel heat flux profile (log-log)

Figure 5. The radial profile of the parallel heat flux measured for the flux tube with $L c=79 \mathrm{~m}$ from experiment 20160224.025 at $290 \mathrm{~ms}$. The green triangles show parallel heat flux measured by the limiter Langmuir probes localized within the same flux tube. To indicate the quality of the fit the profile is shown (a) in semi-log representation with a zoom of the near SOL region and (b) log-log representation 
The sum of the $q_{\|, n}$ and $q_{\|, f}$ represents the parallel heat flux at the LCFS and the parameter $\lambda_{q f}$ and $\lambda_{q n}$ represent the fall-off length for the far and the near SOL. As for $r_{\text {eff }}-r_{\text {eff,LCFS }}$ close to zero.

Interestingly, the double exponential decay is always measured by an infrared camera and only sometimes by the limiter Langmuir probes (LP) [34] (see Fig. 5). The parallel heat flux to the Langmuir probes is calculated using:

$$
\begin{aligned}
q_{\|, \text {Probe }} & =\gamma_{t} k T_{e} \Gamma_{\|} \\
& =\gamma_{t} k T_{e}\left(1+\frac{1}{Z}\right) n_{e} c_{s} \\
& =\gamma_{t} k T_{e}\left(1+\frac{1}{Z}\right) n_{e} \sqrt{\frac{k\left(Z T_{e}+\gamma_{i} T_{i}\right)}{m_{i}}} \\
n_{e} & =\frac{I_{\text {sat }}}{e c_{s} A_{\text {proj. }}} \\
q_{\|, \text {Probe }} & =\gamma_{t} k T_{e} \frac{I_{\text {sat }}}{e A_{\text {proj. }}}\left(1+\frac{1}{Z}\right)
\end{aligned}
$$

with $\mathrm{T}_{i}, T_{e}$, the electron and ion temperature, $\mathrm{Z}=1.5 \pm 0.5$, the average charge of the plasma in front of the probes, $\gamma_{t}$ the heat sheath transmission coefficient, $\gamma_{i}$ the ratio of specific heats for ions, $\mathrm{m}_{i}$ the ion mass (here hydrogen), $\mathrm{I}_{\text {sat }}$ the ion saturation current, $\mathrm{A}_{\text {proj. }}$ the projected collective surface of the probe and $\mathrm{n}_{e}$ the electron density. To avoid assumption on the ion temperature and ratio of specific heat for the ions, the last expression in equation 7 is used. The heat sheath transmission was set to fit Langmuir probe data to the IR measurements. Since the IR camera results are an integrated result over $20 \mathrm{~ms}$, an average of the probe data over the same time window is used to calculate the heat sheath transmission factor. $\gamma_{t}$ varies in the far SOL between 1.6 and 9 with a mean value of 3.43 and median of 3.05. To bring the most probes in the far SOL into agreement with the IR profiles, a sheath transmission coefficient of 3.43 is used for the experiment shown in figure 5. From theory, a higher value in the range of 7 would be expected for the $\gamma_{t}[35]$, but on other machines, similar heat sheath transmission factors in the range of 2 to 20 are needed to bring IR results and Langmuir Probe signals into agreement [35]. Since the factor is fitted by forcing the LP result to agree with infrared an underestimation of the parallel heat flux by the IR system would lead to a too low $\gamma_{t}$. One way to validate the IR results is to calculate the integrated load onto the limiter and to use it in the energy balance. This reveals an agreement within $10 \%$ at low heating powers and a miss-match of up to $40 \%$ at high heating power [36]. If this uncertainty is related to the IR observation an increase of $\gamma_{t}$ of $40 \%$ would be possible, resulting in values of 3-5 for the shown experiment. 


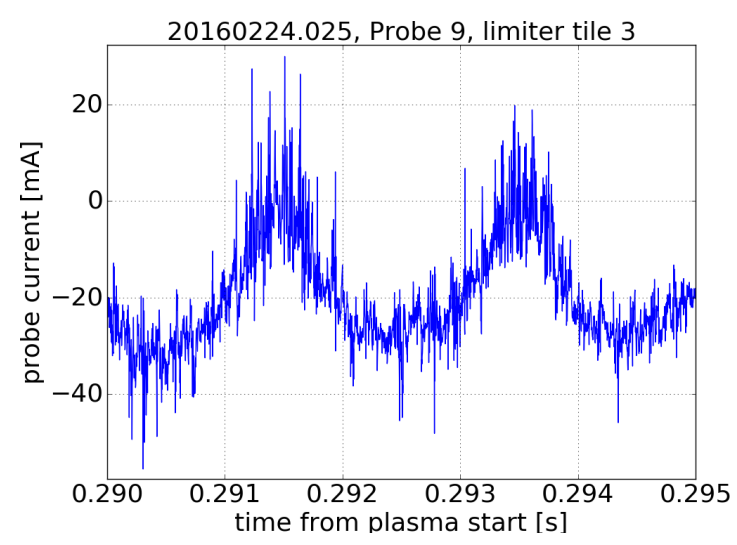

(a) raw signal

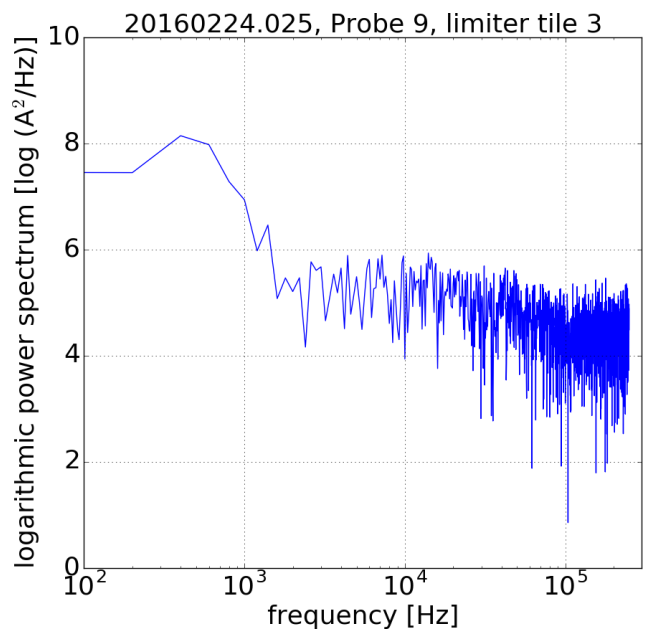

(b) power spectrum

Figure 6. (a) raw signal and (b) power spectrum of the raw signal for probe 9 of limiter tile $3\left(\mathrm{r}_{\text {eff }}=0.43 \mathrm{~cm}\right)$ for experiment 20160224.025

The IR cameras have only a measurement frequency of $50 \mathrm{~Hz}$, while the limiter Langmuir Probes in W7-X are sampled with 250 or $500 \mathrm{kHz}$ and the signal got swept with $500 \mathrm{~Hz}$ for the most time of the campaign. A higher sample frequency allows to investigate the presence of intermittent and turbulent transport [37, 38, as soon their frequency is below the sampling frequency. Figure 6 shows the unprocessed current signal and power spectrum of probe nine on limiter tile three, which is at the location where the near SOL feature starts in the IR observation. The power spectrum shows one broad peak at the sweeping frequency of $500 \mathrm{~Hz}$. Other frequency in the resolvable frequency range does not appear with a high enough amplitude to be distinguished from noise. The rest of the paper will focus on the IR results since no further information is shown by the Langmuir probes and because the LP does not show the near SOL feature.

There are some possible reasons why W7-X limiter Langmuir probes do not measure $q_{\|, \text {near }}$ :

- The probes close to the LCFS was recessed a little bit 34 to protect them; therefore they had a low signal and have mainly seen the perpendicular transport

- The probes near $\mathrm{r}_{e f f}=0.4 \mathrm{~cm}$ were strongly eroded and therefore have unknown collection areas for the flux 34]

- The probes get hot and start to emit electrons, which changes the probe characteristic. Especially the probes in the near SOL had molten steel screens [34]

Lack of near SOL in W7-X Langmuir probe measurements is in contradiction to COMPASS results with inner wall limiter [6]. However, at W7-X also EMC3-EIRENE simulations cannot reproduce the near SOL near the limiter surface. The mechanism, which leads to the formation of near SOL is not included in the models applied in EMC3EIRENE. 


\section{Dependence of radial fall-off length on plasma parameters}

Good wall conditions are necessary to limit the outgassing of the limiters and the wall, decreasing the radiated fraction and therefore increase the coupling of the limiter with the plasma. The analyzed plasma parameters are: the ECRH power $\mathrm{P}_{E C R H}$ as input power, the connection length $\mathrm{L}_{C}$ of the different flux tubes, the density $\mathrm{n}_{e}$ and electron temperature $\mathrm{T}_{e}$ measured by the Thomson scattering (TS) $1.3 \mathrm{~cm}$ inside the LCFS, the toroidal current I, the ion temperature measured by the X-ray imaging spectrometer (XICS), the load on the limiters $\mathrm{P}_{\text {lim }}$ and the loss fraction $f_{\text {loss }}$, which covers the energy losses like radiation, fast particle and charge exchange losses. The loss fraction is defined as:

$$
f_{\text {loss }}=\frac{P_{E C R H}-P_{\text {Lim }}}{P_{E C R H}}
$$

The load on the limiters are calculated by integrating all taken heat flux profiles along the profiles and in poloidal direction. Since only the left half of one limiter is observed, the integration is scaled up to the full machine using the stellarator symmetry for the other half of the limiter and thermo couple information to know the load ratio between the five limiters. The thermo couples measured the temperature at the back side of each limiter and the temperature increase over a experiment represents the integrated load to this limiter. The load asymmetry can be calculated from the differences in the temperature rise. This leads to an asymmetry or up-scaling factor of 4.88 for the load from Limiter 5 to all limiters, because limiter 5 received a little more than the mean load [28].

The range of the different parameters is summarized in table 1, and some example scaling behaviors are shown in figure 7 .

In order to investigate the influence of the connection length LC on the fall-off length $\lambda_{q}$, the influences of other plasma parameters are removed by choosing very similar discharges with small variations of heating power (1.5 to $2.5 \mathrm{MW}$ ) (left plots in figure 275

For the other six plots, only the fall-off length values for the most extended flux tube are shown. 
Table 1. range of the plasma parameters of the used experiments in the database

\begin{tabular}{cccc}
\hline parameter & unit & values & diagnostic \\
\hline$P_{E C R H}$ & $\mathrm{MW}$ & $0.6-4.2$ & ECRH bolometer [40] \\
$n_{e_{\text {edge }}}$ & $10^{18} \mathrm{~m}^{-3}$ & $1.7-10$ & $\mathrm{TS} 41]$ \\
$T_{\text {e}_{\text {edge }}}$ & $\mathrm{keV}$ & $0.02-0.22$ & $\mathrm{TS}[41]$ \\
$T_{i_{\text {line }}}$ & $\mathrm{keV}$ & $0.96-1.76$ & XICS[42, 43] \\
$I$ & $\mathrm{kA}$ & $0.16-1.97$ & Rogowski coil [4] \\
$W_{\text {dia }}$ & $\mathrm{kJ}$ & $5.6-234.6$ & diamagnetic loops[44] \\
$P_{\text {lim }}$ & $\mathrm{MW}$ & $0.18-1.6$ & IR camera [22, 24] \\
$f_{\text {loss }}$ & $\%$ & $47-79$ & eq. 8$]$ \\
$L_{c}$ & $\mathrm{~m}$ & $36,42,79$ & FLT[32] \\
\hline
\end{tabular}

The far fall-off length increases with the connection length and decreases with the input power and density. In case of the near SOL fall-off length, the scaling is rather weak. The dependency on connection length, input power, and density is not explicit, but it decreases with the electron temperature.

To investigate more parameters and to find correlated parameters, a correlation analysis is performed onto the database. A similar method of correlation analysis has also been performed to find an empirical scaling law for the fall-off lengths in tokamaks [10]. The correlation between measured parameters are calculated in the following form:

$$
r_{X Y}=\frac{\sum_{i=1}^{N}\left(X_{i}-\bar{X}\right)\left(Y_{i}-\bar{Y}\right)}{(N-1) s_{x} s_{y}}
$$

With $\mathrm{N}$ being the number of measurements, $\mathrm{X}, \mathrm{Y}$ two different parameters from the database, $\bar{X}, \bar{Y}$ are the mean of the parameters and $s_{X}, s_{y}$ are the corrected standard deviations of parameters. The results are shown in table 2. Each combination of parameters in this table represents the correlation between the two parameters. Everything above $50 \%$ or below $-50 \%$ can be seen as not independent and is therefore written in bold numbers. One thing to point out here, is the strong correlation between input power and density, meaning that if the input power is increased, the density is also increased and vice versa. The nearly linear behavior between density and input power is caused by density restrictions to avoid radiative collapses, meaning that the input power was doubled, if the target density was doubled. Since the connection length is set by the external coil setting; it is constant between the analyzed discharges to zeroth order. Therefore it does not correlate with the other plasma parameters (correlation of 0 in table 2). This table is also used to identify parameters which show a scaling with the measured power fall-off lengths and heat flux density at the LCFS for the near and far SOL. For the fall-off length in the far SOL, the parameters with the highest correlation are the input power $\mathrm{P}$, the diamagnetic energy, the load on the limiter, the connection length, and the time. Latter is a proxy for different parameters as plasma current, impurity concentration, radiative losses, and other unresolved parameters which are changing in time. For the 

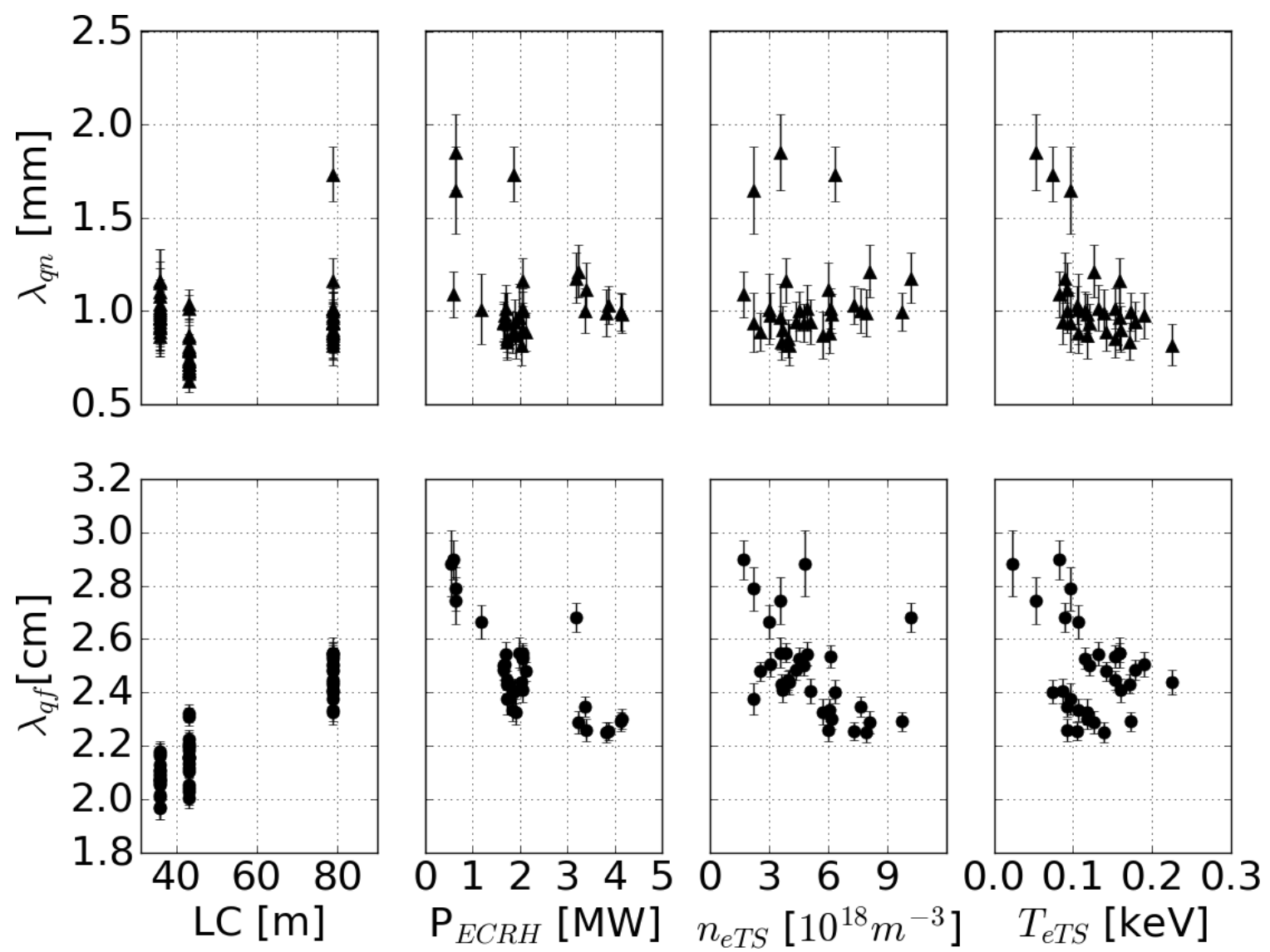

Figure 7. dependencies of the fall-off length for near and far SOL on different measured plasma parameters in the limiter campaign of Wendelstein $7-\mathrm{X}$. The plots against connection length are filtered for input powers between 1.5 and 2.5 MW to limit the scattering. In the remaining plots only the power fall-off length values for the flux tube with a connection length of $79 \mathrm{~m}$ are shown.

near SOL power fall-off length, the highest correlation has been found for the electron temperature near the LCFS, followed by the load on limiters. All other parameters in the table show a rather weak dependency. The parameters with the highest correlation for the fractions of heat flux densities at the LCFS $\left(q_{n}\right.$ and $\left.q_{f}\right)$ are the input power, power to the limiters, density, and ion temperature and electron temperature.

To find a scaling a fit function in the form of a power law is used in the following form:

$$
\lambda_{q}=c \prod_{i=1}^{n} A_{i}^{e_{i}}
$$

With c being a factor for unresolved parameters, $A_{i}$ the plasma parameter, $e_{i}$ the fitting parameter, the exponent for the plasma parameter and $n$ the number of included plasma parameters. The fitting of the scaling law to the data in the database is performed in the logarithmic polynomial form to linearise the fitting equation:

$$
\log \lambda_{q}=\log c+\sum_{i=1}^{n} e_{i} \log A_{i}
$$


Table 2. correlation between the different measured plasma parameters and magnetic field constants. Correlations over $50 \%$ are written in bold numbers

\begin{tabular}{c|ccccccccc|cc|cc}
\hline cor.\% & $n_{\text {edge }}$ & $T_{\text {eedge }}$ & $T_{i}$ & $\mathrm{I}$ & $W_{\text {dia }}$ & $P_{\text {lim }}$ & $f_{\text {loss }}$ & $L_{C}$ & time & $\lambda_{q n}$ & $\lambda_{q f}$ & $q_{n}$ & $q_{f}$ \\
\hline $\mathrm{P}_{\text {ECRH }}$ & $\mathbf{7 7}$ & 21 & -44 & -47 & $\mathbf{7 9}$ & $\mathbf{8 8}$ & 37 & 0 & -36 & -43 & $\mathbf{- 5 5}$ & $\mathbf{8 2}$ & $\mathbf{9 3}$ \\
$n_{\text {edge }}$ & & -8 & -8 & -41 & $\mathbf{7 8}$ & $\mathbf{6 5}$ & 46 & 0 & -32 & -14 & -37 & 48 & $\mathbf{6 0}$ \\
$T_{\text {eedge }}$ & & & -34 & -29 & 22 & 36 & -21 & 0 & -22 & $-\mathbf{5 6}$ & -25 & 35 & 35 \\
$T_{i}$ & & & & 3 & 0 & -34 & -18 & 0 & 15 & 27 & 29 & $\mathbf{- 5 0}$ & -47 \\
$I$ & & & & & $-\mathbf{5 2}$ & -37 & -45 & 0 & $\mathbf{7 6}$ & 12 & 36 & -33 & -38 \\
$W_{\text {dia }}$ & & & & & & $\mathbf{7 1}$ & 35 & 0 & -41 & -36 & -48 & $\mathbf{5 7}$ & $\mathbf{7 2}$ \\
$P_{\text {lim }}$ & & & & & & & -5 & 0 & -24 & -45 & -48 & $\mathbf{7 8}$ & $\mathbf{9 3}$ \\
$f_{\text {loss }}$ & & & & & & & & 0 & $\mathbf{- 5 5}$ & 0 & -34 & 11 & 12 \\
$L_{C}$ & & & & & & & & & 0 & 3 & $\mathbf{6 5}$ & 18 & 7 \\
time & & & & & & & & & & 15 & 45 & -23 & -28 \\
\hline
\end{tabular}

Table 3. results of the fitting for the power fall-off length in the far SOL $\lambda_{q f}$ in cm

\begin{tabular}{cccccccccc}
\hline Reg. & Const. & $\mathrm{P}_{E C R H}$ & $\mathrm{n}$ & $\mathrm{T}_{\text {edge }}$ & $L_{C}$ & $\mathrm{P}_{\text {lim }}$ & $\mathrm{f}_{\text {loss }}$ & $\chi^{2} /$ dof & $R^{2}$ \\
\hline 1 & $1.04(2)$ & $-0.114(5)$ & - & - & $0.22(1)$ & & - & 4.19 & 0.81 \\
2 & $0.92(2)$ & - & - & - & $0.22(1)$ & $-0.09(1)$ & - & 6.73 & 0.71 \\
3 & $0.98(3)$ & $-0.10(1)$ & - & - & $0.22(1)$ & - & $-0.12(2)$ & 3.85 & 0.83 \\
4 & $0.80(2)$ & - & - & - & $0.22(1)$ & $-0.10(1)$ & $-0.33(2)$ & 3.80 & 0.83 \\
5 & $0.74(2)$ & - & $-0.07(1)$ & $-0.05(1)$ & $0.21(1)$ & - & $-0.21(2)$ & 6.02 & 0.73 \\
\hline
\end{tabular}

In this way the multiple regression model can be applied to determine the quality of the fit. A scan for each plasma parameter has been performed, including a combination of parameters up to a number of four parameters. For both regions in the SOL, the regression model is applied separately with different combinations of input parameters, with the restriction to avoid cross-correlated parameters. The coefficient of determination $\left(R^{2}\right)$ and the reduced chi-square $\left(\chi^{2} / d o f\right.$, dof $=$ degree of freedom) are calculated to test and compare the quality of the different fits. Latter includes the number of freedom and the assumptions for the error. The values to fit for the measured fall-off length in the far SOL reaches from $1.82 \mathrm{~cm}$ for the shortest connection length flux tube up to $2.9 \mathrm{~cm}$ for the long connection length flux tube. Table 3 shows the four best fitting function for the power fall-off length in the far SOL, which has been found during the analysis. The error for each parameter is shown in the brackets, where the digits in the brackets represent the error of the last digits. The connection length can be combined with any of the other parameters, because it is unrelated to the rest of the plasma parameters (see table 2). The input power cannot be combined with density, the diamagnetic energy or the load on the limiter due to it high correlation $(77 \%, 79 \%$ and $88 \%)$. The loss fraction is also not independent on the input power, but is nearly independent from the limiter loads. This is also the reason for the strong variation of the exponent for the loss fraction in regression 3 
Table 4. results of the fitting for the power fall-off length in the near SOL $\lambda_{q n}$ in $\mathrm{mm}$

\begin{tabular}{cccccccccc}
\hline Reg. & Const. & $\mathrm{P}_{E C R H}$ & $\mathrm{n}$ & $\mathrm{T}_{e_{\text {edge }}}$ & $L_{C}$ & $\mathrm{P}_{\text {lim }}$ & $\mathrm{T}_{i}$ & $\chi^{2} /$ dof & $R^{2}$ \\
\hline 1 & $0.41(3)$ & $-0.21(2)$ & - & $-0.46(3)$ & - & - & - & 5.15 & 0.54 \\
2 & $0.35(2)$ & - & - & $-0.43(3)$ & - & $-0.21(3)$ & - & 5.35 & 0.52 \\
3 & $0.24(2)$ & - & - & $-0.58(3)$ & - & - & $0.49(8)$ & 5.41 & 0.52 \\
4 & $0.30(2)$ & - & - & $-0.45(3)$ & - & $-0.21(3)$ & $0.35(8)$ & 5.16 & 0.58 \\
5 & $0.36(3)$ & $-0.23(3)$ & - & $-0.49(3)$ & - & - & $0.25(8)$ & 4.83 & 0.60 \\
\hline
\end{tabular}

and 4. The combination of limiter power, connection length, and loss fraction into the fit gives the best representation of the fall-off length for the given data-set, which reaches a coefficient of determination of $83 \%$. A density dependence has not been found, due to its strong correlation with the input power. The resulting found scaling law for the fall-off length in the far SOL is therefore given by:

$$
\lambda_{q f}[\mathrm{~cm}]=(0.79 \pm 0.02) L_{C}^{0.22 \pm 0.01}[\mathrm{~m}] P_{\text {lim }}^{-0.10 \pm 0.01}[M W] f_{\text {loss }}^{-0.34 \pm 0.02}
$$

and is visualized in figure 8(b), The analysis is repeated for the data of the near SOL in a similar way. For the near SOL the measured power fall-off length ranges from $0.6 \mathrm{~mm}$ up to $3.6 \mathrm{~mm}$. The respectively larger error bars have to be taken into account in the fit. The error is larger, due to resolution limitations of the DIAS view, in this small region. The main findings are summarized in table 4. Since the electron temperature showed the highest correlation value for the near SOL power fall-off length it is used in all presented regressions. The line integrated ion temperature is one of the few parameters, which have a positive scaling with the fall-off length and the effects of input power or load on the limiters are also much weaker than in the far SOL scaling. The best found power law for the near SOL is given by electron, ion temperature and heating power:

$$
\lambda_{q n}[m m]=0.36 \pm 0.03 P_{E C R H}^{-0.23 \pm 0.03} T_{i}^{0.25 \pm 0.08} T_{e}^{-0.49 \pm 0.03}
$$

This fit reaches a good reduced chi square value of 4.83 but only a coefficient of determination of $60 \%$. This result implies that not all parameters have been found, which has an effect on the fall-off length. Figure 8(a) visualizes this result including the error bars. The majority of the measured values of $\lambda_{q} n$ are a group of values with less than $1.5 \mathrm{~mm}$. This values are at the limit of the camera resolution after the projection into the plane. A similar analysis can be repeated for the parallel heat flux densities at the LCFS. The values for the fraction from near SOL reaching from $1.8 \mathrm{MW} / \mathrm{m}^{2}$ to $391.8 \mathrm{MW} / \mathrm{m}^{2}$ and the values for the fraction of the far SOL reaching from $1.3 \mathrm{MW} / \mathrm{m}^{2}$ to $22 \mathrm{MW} / \mathrm{m}^{2}$. From table 2 the parameters with the highest influence are input power, density, ion temperature, diamagnetic energy and the limiter load. The majority of these parameters are strongly correlated with the input power, which has the highest influence. The found scaling for the heat flux densities are:

$$
q_{n}\left[M W / m^{2}\right]=(215.55 \pm 13.43) P_{E C R H}^{1.55 \pm 0.02} T_{e}^{0.98 \pm 0.02}\left(R^{2}=85 \%\right)
$$




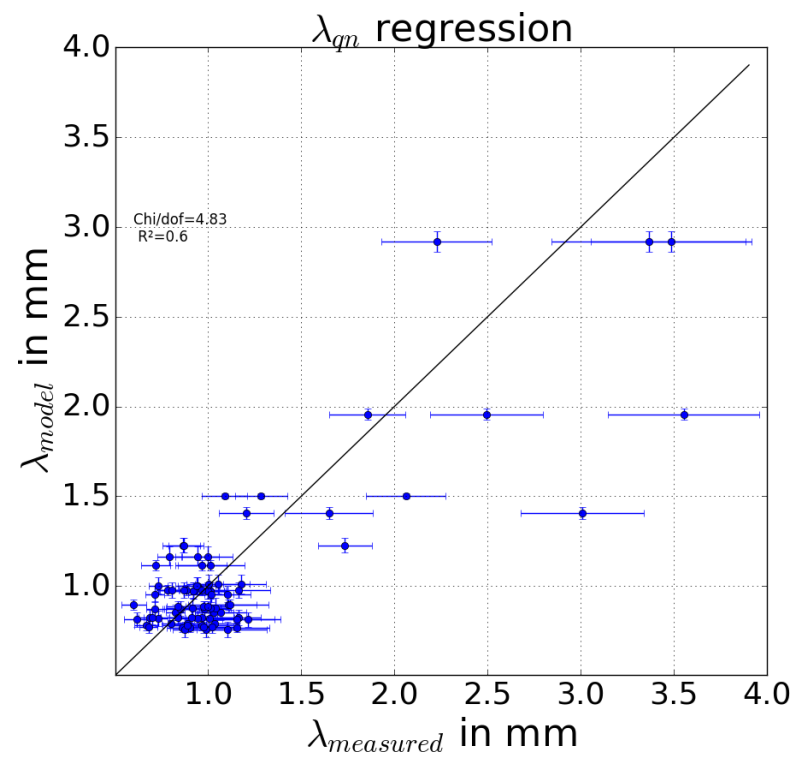

(a) regression result for the near SOL

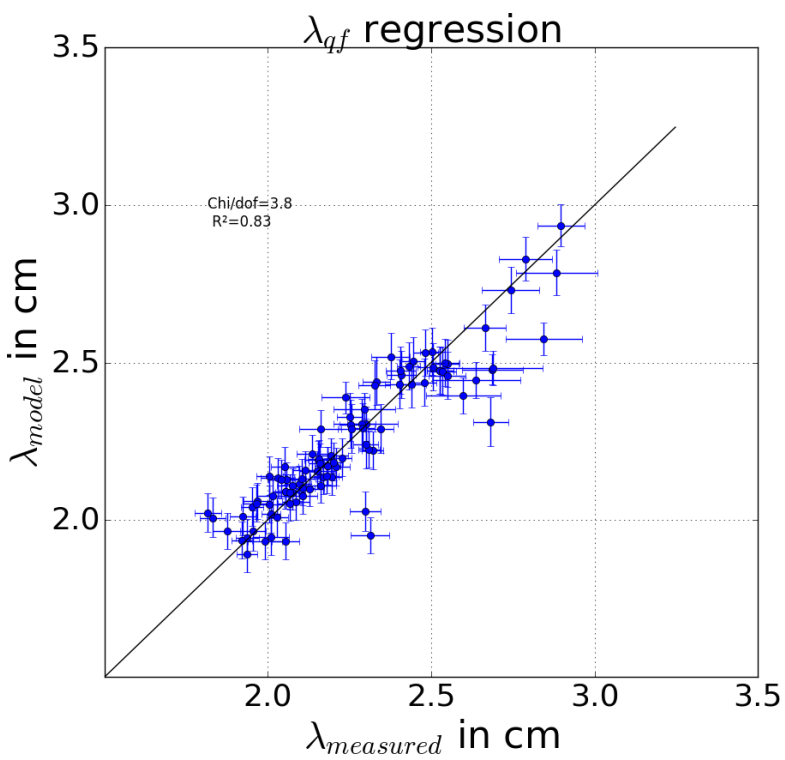

(b) regression result for the far SOL

Figure 8. the two found regression models plotted against the measured values for the power fall-off length.

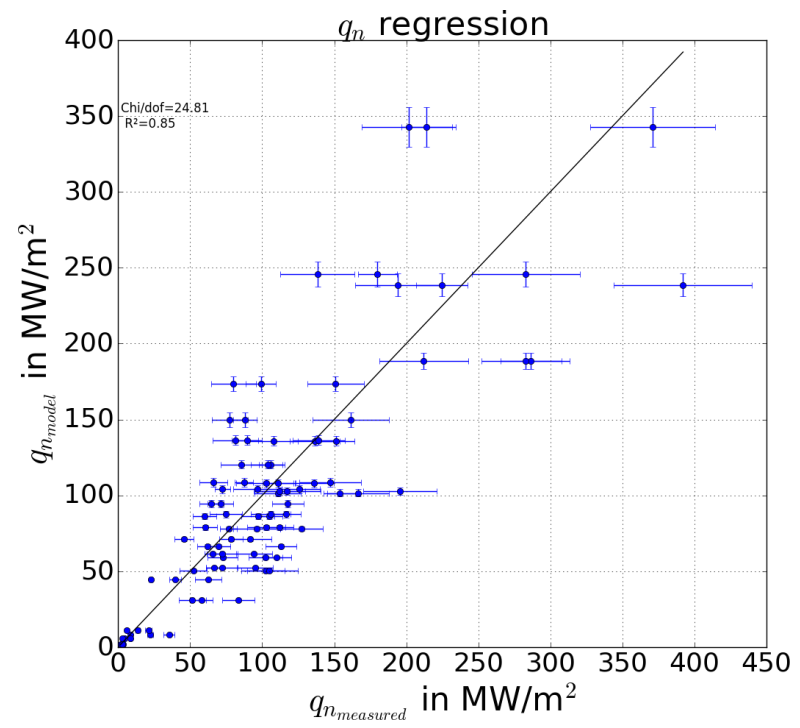

(a) regression result for the near $\mathrm{SOL}$

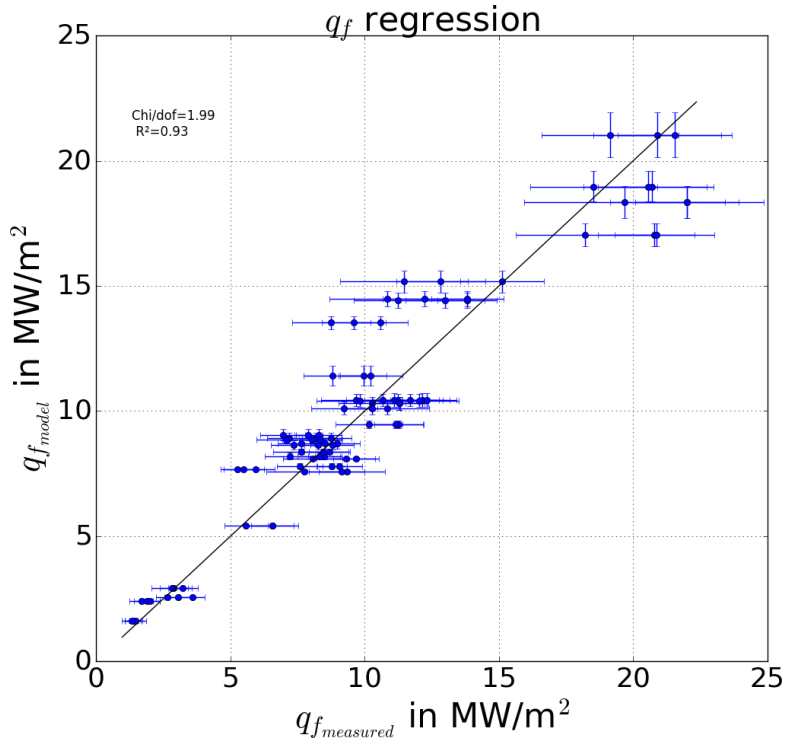

(b) regression result for the far SOL

Figure 9. the two found regression models plotted against the measured values for the heat flux densities close to the LCFS.

$$
q_{f}\left[M W / m^{2}\right]=(8.65 \pm 0.07) P_{E C R H}^{0.975 \pm 0.003} T_{e}^{0.281 \pm 0.004}\left(R^{2}=93 \%\right)
$$

These results are shown in figure 9. The results show, that the found near SOL channel contains a high fraction of the SOL energy $\left(\mathrm{P}_{S O L}\right)$ in a small volume around the LCFS.

To investigate the part of the near SOL, the SOL energy $\mathrm{P}_{S O L}$ has to be computed 
for the W7-X geometry. Since the symmetry approximations from tokamaks do not apply here, the SOL energy is computed by the parallel heat flux profiles and the area which is covered by the flux tubes:

$$
\begin{aligned}
P_{S O L} & =\sum_{i=1}^{\# \text { Limiter \#flux tube types }} \sum_{j=1}^{B_{p o l}} \frac{B_{\theta}}{B_{\phi}} \int_{0}^{r_{\text {wall }}} 2 q_{i j}\left(r_{\text {eff }}^{\prime}\right) \mathrm{d} r_{\text {eff }}^{\prime} \\
& \approx S_{L} \frac{B_{\theta}}{B_{\phi}} \sum_{j=1}^{3} \theta_{j} r_{\text {eff } f_{\text {wall }}}\left(q_{n_{j}} \lambda_{q n_{j}}+q_{f_{j}} \lambda_{q f_{j}}\right)
\end{aligned}
$$

The sum over the limiters covers the complete area of the SOL. The factor two counts for the left and right side of the limiter. The second sum covers the presence of the different flux tubes with different connection length. $\mathrm{L}_{\text {pol }}$ are the poloidal length of a flux tube and the factor $\mathrm{B}_{\theta} / \mathrm{B}_{\phi}$ tilts the projected plane into the field direction. The sum over all limiters is approximated with the symmetry factor $S_{L}$ to work with the measurement of one limiter. It will be five if all limiters get the same load. As described before, the limiter load was not fully symmetric. Therefore the asymmetry factor of 4.88 is used here again. $\theta_{j}$ is the poloidal angle range of the flux tube $\mathrm{j}$ and $r_{\text {ref }} f_{\text {wall }}$ is the effective radius of the outermost flux surface (see the outermost, by limiter intersected flux surface in figure 1(a). Similarly, the additional near SOL energy is calculated:

$$
\begin{aligned}
\Delta P_{S O L} & =\sum_{i=1}^{\# \text { Limiter \#flux tube types }} \sum_{j=1}^{L_{p o l}} \frac{B_{\theta}}{B_{\phi}} \int_{0}^{r_{\text {wall }}} 2\left(q_{i j}\left(r_{\text {eff }}^{\prime}\right)-q_{i j_{f}}\left(r_{\text {eff }}^{\prime}\right)\right) \mathrm{d} r_{\text {eff }}^{\prime} \\
& \approx S_{L} \frac{B_{\theta}}{B_{\phi}} \sum_{j=1}^{3} \theta_{j} r_{\text {eff } f_{\text {wall }}}\left(q_{n_{j}} \lambda_{q n_{j}}\right)
\end{aligned}
$$

The results for the power in the near SOL are summarized in figure 10. It reaches from $17 \mathrm{~kW}$ to $554 \mathrm{~kW}$, meaning that this near SOL carries between $17 \%$ and $38 \%$ of the total SOL power. With increasing input power, the power in the near SOL increases more than linear, resulting in a higher fraction of energy in the near SOL with increasing heating power.

\section{Discussion}

The calculated scaling laws for the power fall-off length of the near and far SOL show no dependency on the density. Other studies on tokamaks show, on the other hand, a clear dependence of the near and far SOL power fall-off length on the density [5]. This effect has not been seen in the data-set of W7-X, although EMC3-EIRENE calculations show a clear dependency of the far SOL fall-off length on the density (figure 11). The reason for this is probably the strong coupling of the density with the input power, which suppresses the effect of the density. The found positive scaling of the main SOL with connection length is qualitatively in agreement with the EMC3-EIRENE scaling, which is given by:

$$
\lambda_{q} \sim \sqrt{D L_{C}} \sim D^{0.5} L_{C}^{0.5}
$$




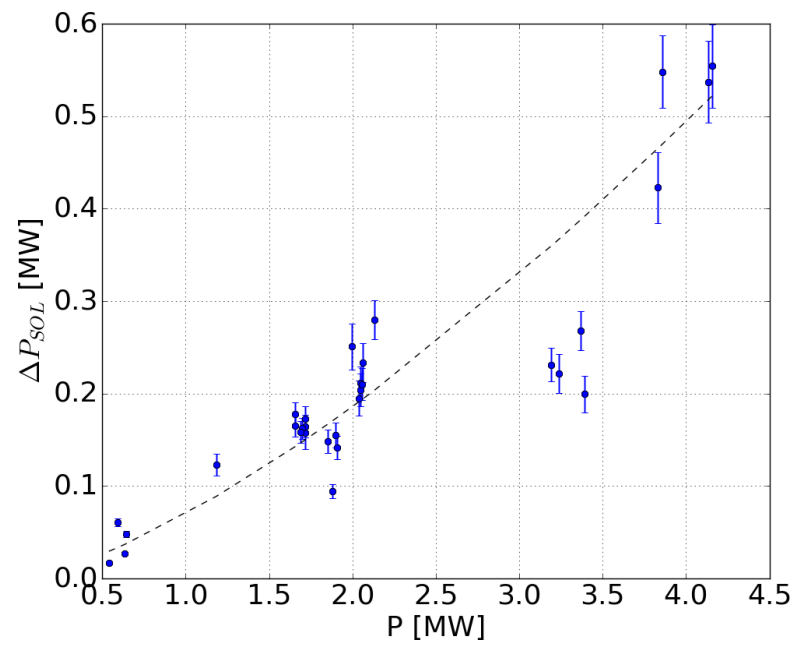

(a) additional near $\mathrm{P}_{S O L}$ energy

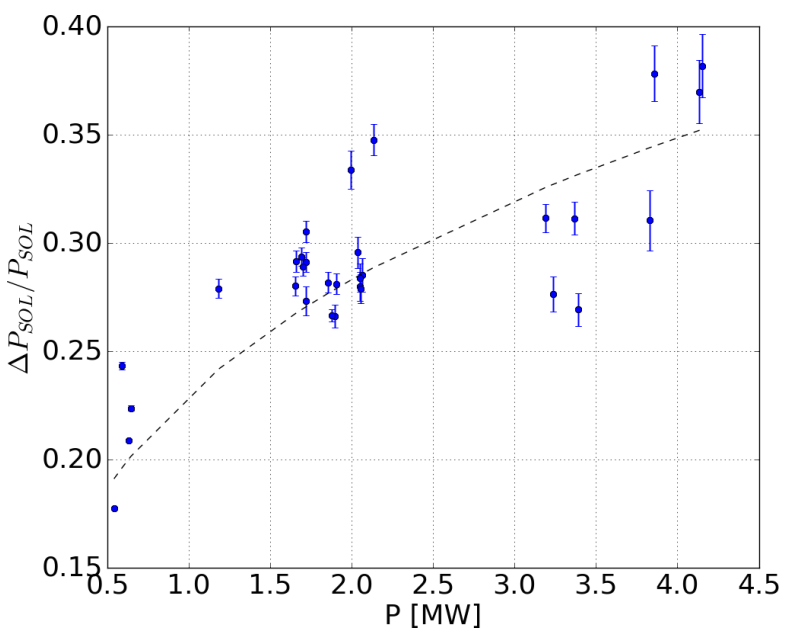

(b) relative fraction of the near SOL energy

Figure 10. Power added by the near SOL in absolute and relative to the total Power in the SOL

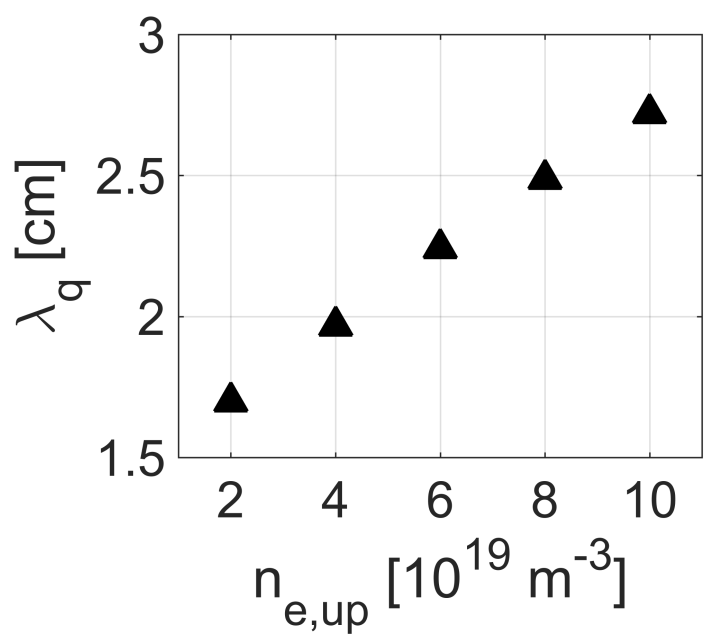

Figure 11. power fall-off length from EMC3-EIRENE for different up-stream densities. $\mathrm{P}=3.2 \mathrm{MW}, \mathrm{D}=1.5 \mathrm{~m}^{2} / \mathrm{s}$

with $\mathrm{D}$ being the diffusion coefficient. However, the measurements show a factor two lower scaling factor. The factor can differ due to a change of the anomalous diffusion. The effect of the anomalous diffusion was not investigated due to missing measurements of this quantity. Another reason could be the fact that the scaling is based on only three values. Also, the strong relation with the plasma current in tokamaks has not been seen in W7-X, since the plasma current is two orders of magnitude smaller in a stellarator. In tokamaks, the scaling for the fall-off length depends strongly on the plasma current $\mathrm{I}_{p}$ and therefore on the poloidal field $\mathrm{B}_{p}[10$. The current effect in a tokamak can be separated into a heating component $\mathrm{P}_{i n}$ and a poloidal field component $\mathrm{B}_{p}$ for the scaling. The latter is related to the connection length $\mathrm{L}_{c}$. The connection length $\mathrm{L}_{c}$ decreases with increasing poloidal field $\mathrm{B}_{p}$ because the field lines twist get stronger in cylindrical limiter 


\begin{tabular}{|c|cccc|}
\hline far SOL model & $\mathrm{C}_{L}$ & $\mathrm{C}_{T}$ & $\mathrm{C}_{n}$ & $\mathrm{C}_{P}$ \\
\hline empirical [10] & 0.40 & -0.51 & -0.1 & 0 \\
theoretical [11], eq.(10) & $0.84(3)$ & $0.06(6)$ & $0.07(1)$ & 0 \\
model fit [11], eq.(11) & $0.76(6)$ & $0.10(6)$ & $0.02(2)$ & 0 \\
\hline experimental W7-X & $0.22(1)$ & 0 & 0 & $-0.10(1)$ \\
\hline near SOL model & $\mathrm{C}_{L}$ & $\mathrm{C}_{T}$ & $\mathrm{C}_{n}$ & $\mathrm{C}_{P}$ \\
\hline HD model [8], eq. (1) & 1 & 0.5 & 0 & 0 \\
HD model [8], eq. (5) & 1.125 & 0 & 0 & 0.125 \\
mod. HD [5] & 1.125 & 0.66 & -0.33 & 0.125 \\
theoretical [9], eq. (8) & 0.25 & -0.125 & 0 & 0 \\
\hline experimental W7-X & 0 & $-0.49(3)$ & 0 & $-0.21(3)$ \\
\hline
\end{tabular}

Table 5. different scalings from experimental and theoretical models for the power fall-off length in the far SOL (top) and the near SOL(bottom

plasma. This lead to the following relation:

$$
\lambda_{q} \sim \frac{1}{I_{p}{ }^{a}} \sim \frac{1}{P_{i n}{ }^{b} B_{p}{ }^{c}} \sim \frac{L_{C}{ }^{d}}{P_{i n}{ }^{b}}
$$

With a,b,c and $d$ as the scaling factors. Based on relations, it is expected that $a=c=d$, with values near unity. Using the relation between poloidal field, plasma current, and the connection length, the tokamak scaling laws can be transformed into a form which can be compared to the results presented in section 5. In a similar way, the safety factor q will be related to the poloidal field, plasma current and therefore to the connection length. For the comparison of the far SOL scaling, the empirical scaling shown in [10] and the theoretical, turbulence driven model from [11] are used. In case of the near SOL, the HD model [8], the modified HD model used in [5] and the model presented in [9] are used for comparison. All models are reduced to measurable plasma parameters in W7-X, and the limiter load will be set equal with the power in the SOL. This restriction includes ignoring any machine size or field strength dependent parameters. Therefore the models are expressed in the following form:

$$
\lambda_{q} \sim L_{C}^{C_{L}} T_{e}^{C_{T}} n_{e}^{C_{n}} P_{S O L}^{C_{P}}
$$

with $C_{X}$ as scaling factors. The models for the far and near SOL and summarized in table 5. The relations in the table show the agreement between the presented results and the tokamak research for the far fall-off length. All models for the far SOL show a positive scaling with connection length, but with different scaling parameters. The dependency on electron density and electron temperature differ between the models and is within the errors bars close to zero in the theoretical model. A similar behaviour is also found in the $\mathrm{W} 7-\mathrm{X}$ results. The main difference is the scaling with the power entering the SOL, which show no scaling in the tokamak models but show a clear dependency in W7-X.

For the near SOL scalings, all compared tokamaks models show a positive scaling on the connection length, while the results found in W7-X show no clear scaling with 
$\mathrm{L}_{C}$. The HD model and the modified model from TCV suggest an opposite scaling of the near SOL with power and electron temperature compared to the results presented here for W7-X. Only the theoretical model, which includes assumptions on turbulence, show a similar trend for the electron temperature dependence, but with a smaller scaling factor.

This similarity of the scalings suggests that turbulent effects can play a role in the near SOL behavior. One observed turbulent feature, which can probably affect the near SOL from the first operation campaign are filament structures close to the LCFS [45]. These filament structures rotating around the plasma and have a lifetime in the range of $200 \mu \mathrm{s}$ [45], which fit well to the residence time of a particle with the sound speed velocity on an open field line. Filament structures are also known from tokamaks, and their formation and separation can be related to the effective collisionality of the plasma [46, 47]. If the effective collisionality gets close to unity, the filaments can leave the plasma and propagate outward. In tokamaks, these filaments stay on the outboard side and do not propagate to the inboard side, which is different for W7-X. Figure 12(a) show the main plasma parameters for an experiment, where the biggest change of the near SOL fall-off length has been seen. In this program, a power step has been performed, resulting in a decreasing electron temperature at a constant density. This effect increases the collisionality, and near SOL fall-off length increases also. The collisionality is approaching unity near the end of the plasma. To investigate the behavior of the filament, the H-alpha signal is analyzed before and after the power step (see figure 12(b)). The probability distribution function (PDF) of H-alpha signal shows a positive skewness, which can be caused by the presence of filaments. The PDF does not change much before and after the power step, suggesting no significant change or decoupling of the filaments from the plasma. Assuming that the filaments play a role in the near SOL feature, suggest that the enlargement of the fall-off length is caused by the radial movement or size change of the filament. Since the temperature decreases, the parallel velocity of the filaments also decreases, resulting in a longer lifetime. A longer lifetime means more radial displacement and a larger near SOL fall-off length. The filament explanation is just one possible option for the enhancement, which has to be further described by a turbulent theory, but this is out of the scope of this paper.

\section{Conclusion}

In this paper, the first measurements of the power fall-off length in the limiter phase of the advanced stellarator Wendelstein 7 -X have been presented. It was shown that two different fall-off regimes were measured for the inner wall limiter configuration: a near SOL and a far SOL, similar to the measurements on tokamaks for inboard limiters. The measured power fall-off length in the near SOL reaches from 0.6(5) $\mathrm{mm}$ up to 3.6(5) mm and is in the far SOL a magnitude larger with values from 18.2(5) $\mathrm{mm}$ to $29.0(5) \mathrm{mm}$. The effect of the wall to wall connection length together with loads to the limiter as a proxy for the power in the SOL have been shown as main parameters, which are affecting the far fall-off length. A qualitative agreement with EMC3-EIRENE modeling and with 


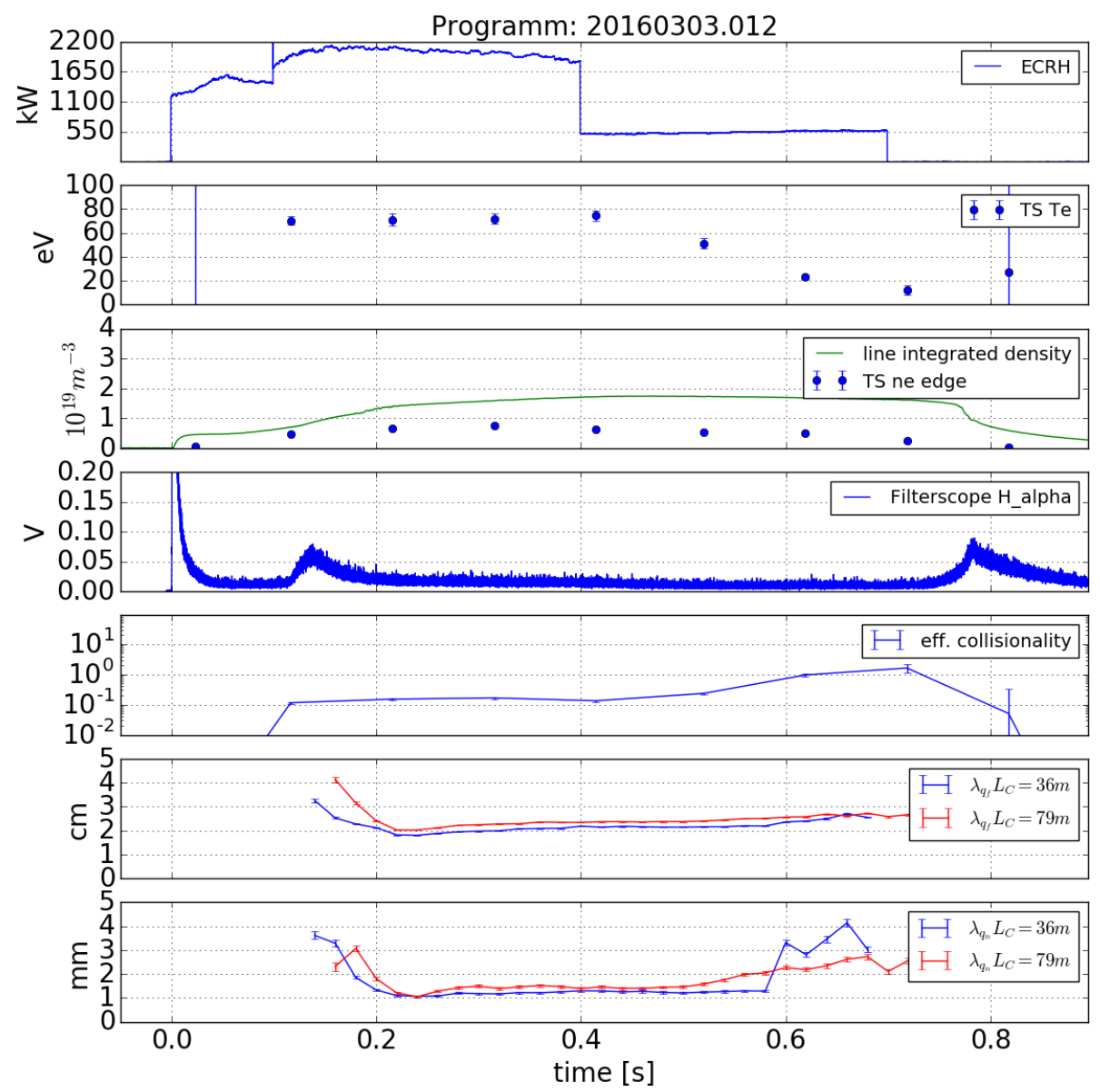

(a) overview plot, 20160303.012

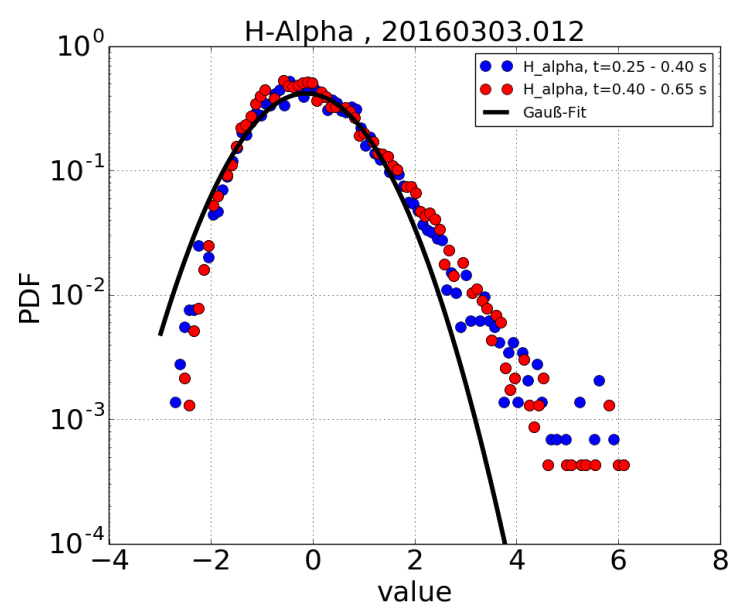

(b) PDF of the H-alpha signal

Figure 12. (a) traces for different plasma diagnostics for the experiment 20160303.012. From top to bottom: (1) input power, (2) edge electron temperature, measured by Thomson Scattering, (3) line integrated density and edge density, (4) H-Alpha signal from filter scope system 48, (5) effective collisionality, (6) far SOL power fall-off length, (7) near SOL power fall-off length. A power step down is performed, resulting in a higher collisionality and an increase of the near SOL fall-off length (b) probability distribution function (PDF) of the $\mathrm{H}$-alpha signal, before and after the power step. 
tokamak models for the main SOL scaling with connection length was shown. For the near SOL, it was shown that the electron temperature near the last closed flux surface plays a dominant role in the behavior of this narrow regime. This dominant-negative scaling with electron temperature is a contrast to the HD-model in tokamaks, which has a good agreement with tokamak results. As a consequence, a different origin of the near SOL in W7-X is expected, which can be turbulent driven. It has also been shown that this near SOL regime contains up to $38 \%$ of the power in the SOL. It is not covered by 3D-Modelling, due to a missing physics model for the formation of this near SOL feature.

\section{Acknowledgments}

This work has been carried out within the framework of the EUROfusion Consortium and has received funding from the Euratom research and training program 2014-2018 and 2019-2020 under grant agreement No 633053. The views and opinions expressed herein do not necessarily reflect those of the European Commission. This work was supported in part by the U.S. Department of Energy (DoE) under grant DE-SC0014210 and by discretional funding of the Department of Engineering Physics and the College of Nuclear Engineering at the University of Wisconsin - Madison, USA.

\section{References}

[1] A. Loarte, B. Lipschultz, A. Kukushkin, G. Matthews, P. Stangeby, N. Asakura, G. Counsell, G. Federici, A. Kallenbach, K. Krieger, A. Mahdavi, V. Philipps, D. Reiter, J. Roth, J. Strachan, D. Whyte, R. Doerner, T. Eich, W. Fundamenski, A. Herrmann, M. Fenstermacher, P. Ghendrih, M. Groth, A. Kirschner, S. Konoshima, B. LaBombard, P. Lang, A. Leonard, P. Monier-Garbet, R. Neu, H. Pacher, B. Pegourie, R. Pitts, S. Takamura, J. Terry, E. Tsitrone, the ITPA Scrape-off Layer, D. Group, Chapter 4: Power and particle control, Nuclear Fusion 47 (6) (2007) S203-S263. doi:10.1088/0029-5515/47/6/s04. URL https://doi .org/10.1088\%2F0029-5515\%2F47\%2F6\%2Fs04

[2] M. Kocan, R. Pitts, G. Arnoux, I. Balboa, P. de Vries, R. Dejarnac, I. Furno, R. Goldston, Y. Gribov, J. Horacek, M. Komm, B. Labit, B. LaBombard, R. Lasnier, C.J.and Mitteau, F. Nespoli, D. Pace, R. Panek, P. Stangeby, J. Terry, C. Tsui, P. Vondracek, Impact of a narrow limiter SOL heat flux channel on the ITER first wall panel shaping, Nuclear Fusion 55 (2015) 033019.

[3] G. Arnoux, T. Farley, C. Silva, S. Devaux, M. Firdaouss, D. Frigione, R. Goldston, J. Gunn, J. Horacek, S. Jachmich, P. Lomas, S. Marsen, G. Matthews, R. Pitts, M. Stamp, P. Stangeby, JET-EFDA Contributors, Scrape-off layer properties of ITER-like limiter start-up plasmas in JET, Nuclear Fusion 53 (2013) 073016.

[4] F.Nespoli, B.Labit, I.Furno, G.P.Canal, A.Fasoli, the TCV team, Heat loads in inboard limited Lmode plasmas in TCV, Journal of Nuclear Materials 463 (2015) 393-396. doi:https://doi.org/ 10.1016/j.jnucmat.2014.11.137.

[5] F. Nespoli, B. Labit, I. Furno, J. Horacek, C. Tsui, J. Boedo, R. Maurizio, H. Reimerdes, C. Theiler, P. Ricci, F. Halpern, U. Sheikh, K. Verhaegh, R. Pitts, F. Militello, T. E. M. Team, T. T.

n Team, Understanding and suppressing the near scrape-off layer heat flux feature in inboard-limited plasmas in tcv, Nuclear Fusion 57 (12) (2017) 126029. URL http://stacks .iop.org/0029-5515/57/i=12/a=126029

[6] J. Horacek, P. Vondracek, R. Panek, R. Dejarnac, M. Komm, R. Pitts, R. Goldston, P. Stangeby, E. Gauthier, P. Hacek, J. Havlicek, M. Hron, M. Imrisek, F. Janky, J. Seidl, Narrow heat flux 
channels in the COMPASS limiter scrape-off layer, Journal of Nuclear Materials 463 (2015) 385388.

[7] R. Dejarnac, P. Stangeby, R. Goldston, E. Gauthier, J. Horacek, M. Hron, M. Kocan, M. Komm, R. Panek, R. Pitts, P. Vondracek, Understanding narrow sol power flux component in compass limiter plasmas by use of langmuir probes, Journal of Nuclear Materials 463 (2015) 381 - 384, pLASMA-SURFACE INTERACTIONS 21. doi:https://doi.org/10.1016/j.jnucmat.2014. 12.100

URL http://www.sciencedirect.com/science/article/pii/S0022311514010538

[8] R. Goldston, Heuristic drift-based model of the power scrape-off width in low-gas-puff H-mode tokamaks, Nuclear Fusion 52 (1) (2011) 013009. doi:10.1088/0029-5515/52/1/013009. URL https ://doi .org/10.1088/0029-5515/52/1/013009

[9] C. K. Tsui, J. A. Boedo, F. D. Halpern, J. Loizu, F. Nespoli, J. Horacek, B. Labit, J. Morales, H. Reimerdes, P. Ricci, C. Theiler, S. Coda, B. P. Duval, I. Furno, Poloidal asymmetry in the narrow heat flux feature in the tcv scrape-off layer, Physics of Plasmas 24 (6) (2017) 062508. arXiv:https://doi.org/10.1063/1.4985075, doi:10.1063/1.4985075

URL https://doi.org/10.1063/1.4985075

[10] J. Horacek, R. A. Pitts, J. Adamek, G. Arnoux, J.-G. Bak, S. Brezinsek, M. Dimitrova, R. J. Goldston, J. P. Gunn, J. Havlicek, S.-H. Hong, F. Janky, B. LaBombard, S. Marsen, G. Maddaluno, L. Nie, V. Pericoli, T. Popov, R. Panek, D. Rudakov, J. Seidl, D. S. Seo, M. Shimada, C. Silva, P. C. Stangeby, B. Viola, P. Vondracek, H. Wang, G. S. Xu, Y. X. and, Multi-machine scaling of the main SOL parallel heat flux width in tokamak limiter plasmas, Plasma Physics and Controlled Fusion 58 (7) (2016) 074005. doi:10.1088/0741-3335/58/7/074005. URL https ://doi .org/10.1088\%2F0741-3335\%2F58\%2F7\%2F074005

[11] F. D. Halpern, J. Horacek, R. A. Pitts, P. Ricci, A theoretical interpretation of the main scrapeoff layer heat-flux width scaling for tokamak inner-wall limited plasmas, Plasma Physics and Controlled Fusion 58 (8) (2016) 084003. doi:10.1088/0741-3335/58/8/084003. URL https ://doi.org/10.1088\%2F0741-3335\%2F58\%2F8\%2F084003

[12] P. Stangeby, R. Mitteau, Analysis for shaping the iter first wall, Journal of Nuclear Materials 390-391 (2009) 963 -966, proceedings of the 18th International Conference on Plasma-Surface Interactions in Controlled Fusion Device. doi:https://doi.org/10.1016/j.jnucmat.2009.01.249. URL http://www.sciencedirect.com/science/article/pii/S0022311509002748

[13] R. Mitteau, P. Stangeby, C. Lowry, M. Merola, Heat loads and shape design of the iter first wall, Fusion Engineering and Design 85 (10) (2010) 2049 - 2053, proceedings of the Ninth International Symposium on Fusion Nuclear Technology. doi:https://doi.org/10.1016/j.fusengdes. 2010. 07.022 .

URL http://wWw.sciencedirect.com/science/article/pii/S092037961000342X

[14] R. Wenninger, R. Albanese, R. Ambrosino, F. Arbeiter, J. Aubert, C. Bachmann, L. Barbato, T. Barrett, M. Beckers, W. Biel, L. Boccaccini, D. Carralero, D. Coster, T. Eich, A. Fasoli, G. Federici, M. Firdaouss, J. Graves, J. Horacek, M. Kovari, S. Lanthaler, V. Loschiavo, C. Lowry, H. Lux, G. Maddaluno, F. Maviglia, R. Mitteau, R. Neu, D. Pfefferle, K. Schmid, M. Siccinio, B. Sieglin, C. Silva, A. Snicker, F. Subba, J. Varje, H. Zohm, The DEMO wall load challenge, Nuclear Fusion 57 (4) (2017) 046002. doi:10.1088/1741-4326/aa4fb4.

URL https://doi.org/10.1088\%2F1741-4326\%2Faa4fb4

[15] S. Masuzaki, T. Morisaki, N. Ohyabu, A. Komori, H. Suzuki, N. Noda, Y. Kubota, R. Sakamoto, K. Narihara, K. Kawahata, K. Tanaka, T. Tokuzawa, S. Morita, M. Goto, M. Osakabe, T. Watanabe, Y. Matsumoto, O. Motojima, the LHD Experimental group, The divertor plasma 475 characteristics in the large helical device, Nuclear Fusion 42 (6) (2002) 750-758. doi:10.1088/ $0029-5515 / 42 / 6 / 313$

URL https ://doi .org/10.1088\%2F0029-5515\%2F42\%2F6\%2F313

[16] S. Masuzaki, T. Morisaki, M. Shoji, Y. Kubota, T. Watanabe, M. Kobayashi, J. Miyazawa, M. Goto, S. Morita, B. J. Peterson, N. Ohyabu, A. Komori, O. Motojima, L. E. Group, H. Ogawa, Overview and future plan of helical divertor study in the large helical device, Fusion Science 
and Technology 50 (3) (2006) 361-371. arXiv:https://doi.org/10.13182/FST06-A1257, doi: 10.13182/FST06-A1257.

URL https ://doi .org/10.13182/FST06-A1257

[17] M. Hirsch, J. Baldzuhn, C. Beidler, R. Brakel, R. Burhenn, A. Dinklage, H. Ehmler, M. Endler, V. Erckmann, Y. Feng, J. Geiger, L. Giannone, G. Grieger, P. Grigull, H.-J. Hartfuß, D. Hartmann, R. Jaenicke, R. Knig, H. P. Laqua, H. Maaßberg, K. McCormick, F. Sardei, E. Speth, U. Stroth, F. Wagner, A. Weller, A. Werner, H. Wobig, S. Z. and, Major results from the stellarator wendelstein 7-AS, Plasma Physics and Controlled Fusion 50 (5) (2008) 053001. doi:10.1088/ 0741-3335/50/5/053001.

URL https : //doi .org/10.1088\%2F0741-3335\%2F50\%2F5\%2F053001

[18] T. Sunn Pedersen, T. Andreeva, H.-S. Bosch, S. Bozhenkov, F. Effenberg, M. Endler, Y. Feng, D. Gates, J. Geiger, D. Hartmann, H. Hölbe, M. Jakubowksi, R. König, H. Laqua, S. Lazerson, M. Otte, M. Preynas, O. Schmitz, T. Stange, Y. Turkin, W7-X Team, Plans for the first plasma operation of Wendelstein 7-X, Nuclear Fusion 55 (12) (2015) 126001. doi:10.1088/0029-5515/

55/12/126001

URL https : //doi.org/10.1088\%2F0029-5515\%2F55\%2F12\%2F 126001

[19] S. Bozhenkov, M. Jakubowski, H. Niemann, S. Lazerson, G. Wurden, C. Biedermann, G. Kocsis,

口 R. Knig, F. Pisano, L. Stephey, T. Szepesi, U. Wenzel, T. Pedersen, R. W. and, Effect of

[. error field correction coils on w7-x limiter loads, Nuclear Fusion 57 (12) (2017) 126030. doi: $10.1088 / 1741-4326 /$ aa85ce

URL https ://doi.org/10.1088\%2F1741-4326\%2Faa85ce

[20] S. Bozhenkov, F. Effenberg, Y. Feng, J. Geiger, D. Hartmann, H. Hölbe, T. Pedersen, R. Wolf, Limiter for the early operation phase of W7-X, 41st EPS Conf. on Plasma Physics 38F, P-1.080 41. URL http://ocs .ciemat.es/EPS2014PAP/pdf/P1.080.pdf

[21] M. Krychowiak, A. Adnan, A. Alonso, T. Andreeva, J. Baldzuhn, T. Barbui, M. Beurskens, W. Biel, C. Biedermann, B. D. Blackwell, H. S. Bosch, S. Bozhenkov, R. Brakel, T. Bräuer, B. Brotas de Carvalho, R. Burhenn, B. Buttenschön, A. Cappa, G. Cseh, A. Czarnecka, A. Dinklage, P. Drews, A. Dzikowicka, F. Effenberg, M. Endler, V. Erckmann, T. Estrada, O. Ford, T. Fornal, H. Frerichs, G. Fuchert, J. Geiger, O. Grulke, J. H. Harris, H. J. Hartfu, D. Hartmann, D. Hathiramani, M. Hirsch, U. Hfel, S. Jaboski, M. W. Jakubowski, J. Kaczmarczyk, T. Klinger, S. Klose, J. Knauer, G. Kocsis, R. König, P. Kornejew, A. Krämer-Flecken, N. Krawczyk, T. Kremeyer, I. Ksiek, A. Kubkowska, M. Langenberg, H. P. Laqua, M. Laux, S. Lazerson, Y. Liang, S. C. Liu, A. Lorenz, A. O. Marchuk, S. Marsen, V. Moncada, D. Naujoks, H. Neilson, O. Neubauer, U. Neuner, H. Niemann, J. W. Oosterbeek, M. Otte, N. Pablant, E. Pasch, T. Sunn Pedersen, F. Pisano, K. Rahbarnia, L. Ry, O. Schmitz, S. Schmuck, W. Schneider, T. Schrder, H. Schuhmacher, B. Schweer, B. Standley, T. Stange, L. Stephey, J. Svensson, T. Szabolics, T. Szepesi, H. Thomsen, J.-M. Travere, H. Trimino Mora, H. Tsuchiya, G. M. Weir, U. Wenzel, A. Werner, B. Wiegel, T. Windisch, R. Wolf, G. A. Wurden, D. Zhang, A. Zimbal, S. Zoletnik, W7-X Team, Overview of diagnostic performance and results for the first operation phase in Wendelstein 7-X, Rev. Sci. Instrument 87 (2016) 11 D304.

[22] D. Wassilew, U. Hoffmann, D. Hildebrandt, Development of an IR-Microbolometer-Camera for Operation in a Strong Magnetic Field, SENSOR+TEST Conferences 2011 Proceedings IRS, Nürnberg, Germany (2011) IP4doi:10.5162/irs11/ip4. URL https://www . ama-science.org/proceedings/details/390

[23] R. König, J. Baldzuhn, W. Biel, C. Biedermann, R. Burhenn, S. Bozhenkov, J. Cantarini, H. Dreier, M. Endler, H.-J. Hartfuss, D. Hildebrandt, M. Hirsch, M. Jakubowski, R. Jimenez-Gomez, G. Kocsis, P. Kornejev, M. Krychowiak, H. P. Laqua, M. Laux, J. W. Oosterbeek, E. Pasch, T. Richert, W. Schneider, B. Schweer, J. Svensson, H. Thomsen, A. Weller, A. Werner, R. Wolf, D. Zhang, S. Zoletnik, Diagnostics design for steady-state operation of the Wendelstein 7-X stellarator, Rev. Sci. Instrument 81 (2010) 10E133.

[24] H. Niemann, M. Jakubowksi, T. Sunn Pedersen, R. König, G. A. Wurden, F. Effenberg, D. Zhang, 
W7-X Team, Power loads in the limiter phase of Wendelstein 7-X, 43rd EPS Conf. on Plasma Physics (2016) P4.005.

URL http://www . euro-fusionscipub.org/wp-content/uploads/WPS1CP16_15496_ submitted.pdf

[25] M. Jakubowski, P. Drewelow, J. Fellinger, A. Puig Sitjes, G. Wurden, A. Ali, C. Biedermann, B. Cannas, D. Chauvin, M. Gamradt, H. Greve, Y. Gao, D. Hathiramani, R. König, A. Lorenz, V. Moncada, H. Niemann, T. T.Ngo, F. Pisano, T. Sunn Pedersen, Infrared Imaging Systems for wall protection in the W7-X stellarator, Review of Scientific Instruments 89 (2018) 10E116-9.

[26] F. Pisano, B. Cannas, M. W. Jakubowski, H. Niemann, A. Puig Sitjes, G. A. Wurden, Towards a new image processing system at wendelstein 7-x: From spatial calibration to characterization of thermal events, Review of Scientific Instruments 89 (12) (2018) 123503. arXiv:https: //doi.org/10.1063/1.5045560, doi:10.1063/1.5045560. URL https ://doi .org/10.1063/1.5045560

[27] V. R. Winters, S. Brezinsek, F. Effenberg, M. Rasinski, O. Schmitz, L. Stephey, C. Biedermann, C. P. Dhard, H. Frerichs, J. Harris, M. Krychowiak, R. König, T. Sunn Pedersen, G. A. Wurden, W7-X Team, Overview of plasma-surface interaction analyses in the limiter phase of W7-X", Physica Scripta T170 (2017) 014050.

[28] G. A. Wurden, C. Biedermann, F. Effenberg, M. Jakubowski, H. Niemann, L. Stephey, S. Bozhenkov, S. Brezinsek, J. Fellinger, B. Cannas, F. Pisano, S. Marsen, H. Laqua, R. Knig, O. Schmitz, J. Harris, E. Unterberg, W7-X Team, Limiter observations during W7-X first plasmas, Nuclear Fusion 57 (2017) 056036.

[29] A. Herrmann, Limitations for divertor heat flux calculations of fast events in tokamaks, 28th EPS conference on Controlled Fusion and Plasma Physics 25A (2001) 2109-2112. URL http://hdl . handle.net/11858/00-001M-0000-0027-49DD-7

[30] B. Sieglin, M. Faitsch, A. Herrmann, B. Brucker, T. Eich, L. Kammerloher, S. Martinov, Real time capable infrared thermography for ASDEX Upgrade, REVIEW OF SCIENTIFIC INSTRUMENTS 86 (2015) 113502.

[31] F. Effenberg, Y. Feng, O. Schmitz, H. Frerichs, S. Bozhenkov, H. Hölbe, R. Köenig, M. Krychowiak, T. Sunn Pedersen, D. Reiter, L. Stephey, W7-X Team, Numerical investigation of plasma edge transport and limiter heat fluxes in Wendelstein 7-X startup plasmas with EMC3-EIRENE, Nuclear Fusion 57 (2017) 036021.

[32] S. Bozhenkov, J. Geiger, M. Grahl, J. Kilinger, A. Werner, R. Wolf, Service oriented architecture for scientific analysis at W7-X. An example of a field line tracer, Fusion Engineering and Design 88 (2013) 29973006.

[33] D. Zhang, R. Burhenn, A. Alonso, B. Buttenschön, Y. Feng, L. Giannone, M. Hirsch, U. Höfel, R. Lauber, M. Marquardt, K. Rahbarnia, J. Svensson, G. A. Wurden, R. Brakel, O. Grulke, J. Knauer, R. Knig, H. Laqua, S. Marsen, T. Stange, T. Schröder, H. Thomsen, G. Weir, A. Werner, the W7-X Team, The bolometer diagnostic at Wendelstein 7-X and its first results from the initial campaign, stellarator news 157. URL https://stelnews.info/sites/default/files/2017-06/sn157_1.pdf

[34] S. Klose, S. Freundt, D. Hathiramani, M. Laux, M. Endler, B. Blackwell, R. König, T. S. Pedersen, the W7-X Team", Design and results of the limiter langmuir probe diagnostics of w7-x, 43rd EPS Conf. on Plasma Physics (2016) P4.005Poster.

[35] J. Marki, R. Pitts, T. Eich, A. Herrmann, J. Horacek, F. Sanchez, G. Veres, Sheath heat transmission factors on tcv, Journal of Nuclear Materials 363-365 (2007) 382 - 388, plasma-Surface Interactions17. doi:https://doi.org/10.1016/j.jnucmat.2007.01.197. URL http://www.sciencedirect.com/science/article/pii/S0022311507000761

[36] S. A. Bozhenkov, G. Fuchert, H. Niemann, M. Beurskens, Y. Feng, O. Ford, J. Geiger, M. Hirsch, U. Höfel, M. W. Jakubowksi, J. Knauer, P. Kornejew, A. Langenberg, H. P. Laqua, H. Maasberg, N. Marushchenko, D. Moseev, N. Pablant, E. Pasch, K. Rahbarnia, T. Stange, J. Svensson, H. Trimino Mora, P. Valson, G. Wurden, D. Zhang, R. Wolf, W7-X Team, Power Balance Analysis of Wendelstein 7-X Plasmas Using Profile Diagnostics, 43rd EPS Conf. on Plasma Physics (2016) 

16280.

URL http://www. euro-fusionscipub.org/wp-content/uploads/WPS1CP16_16280_ submitted.pdf

[37] V. Budaev, N. Ohno, S. Masuzaki, T. Morisaki, A. Komori, S. Takamura, Extended self-similarity of intermittent turbulence in edge magnetized plasmas, Nuclear Fusion 48 (2) (2008) 024014. doi: $10.1088 / 0029-5515 / 48 / 2 / 024014$

URL https ://doi . org/10.1088\%2F0029-5515\%2F48\%2F2\%2F024014

[38] V. Budaev, L. Zelenyi, S. Savin, Generalized self-similarity of intermittent plasma turbulence in space and laboratoryplasmas, Journal of Plasma Physics 81 (6) (2015) 395810602. doi: 10.1017/S0022377815001099.

[39] T. Wauters, R. Brakel, S. Brezinsek, A. Dinklage, A. Goriaev, H. Laqua, S. Marsen, D. Moseev, T. Stange, G. Schlisio, T. S. Pedersen, O. Volzke, U. W. and, Wall conditioning by ECRH discharges and he-GDC in the limiter phase of wendelstein 7-x, Nuclear Fusion 58 (6) (2018) 066013. doi:10.1088/1741-4326/aab2c9

URL https://doi .org/10.1088\%2F1741-4326\%2Faab2c9

[40] T. Stange, H. P. Laqua, M. Beurskens, H.-S. Bosch, S. Bozhenkov, R. Brakel, H. Braune, K. J. Brunner, A. Cappa, A. Dinklage, V. Erckmann, G. Fuchert, G. Gantenbein, F. Gellert, O. Grulke, D. Hartmann, M. Hirsch, U. Höfel, W. Kasparek, J. Knauer, A. Langenberg, S. Marsen, N. Marushchenko, D. Moseev, N. Pablant, E. Pasch, K. Rahbarnia, H. Trimino Mora, T. Tsujimura, Y. Turkin, T. Wauters, R. Wolf, W7-X-Team, Advanced electron cyclotron heating and current drive experiments on the stellarator Wendelstein 7-X, EPJ Web Conf. 22 Topical Conference on Radio Frequency Power in Plasmas 157 (02008). doi:https://doi.org/10.1051/ epjconf/201715702008.

[41] E. Pasch, M. Beurskens, S. Bozhenkov, G. Fuchert, J. Knauer, R. WOlf, W7-X-Team, The Thomson scattering system at Wendelstein 7-X, Review of Scientific Instruments 87 (11E729). doi:https://doi.org/10.1063/1.4962248.

[42] A. Langenberg, N. A. Pablant, T. Wegner, P. Traverso, O. Marchuk, T. Bruer, B. Geiger, G. Fuchert, S. Bozhenkov, E. Pasch, O. Grulke, F. Kunkel, C. Killer, D. Nicolai, G. Satheeswaran, K. P. Hollfeld, B. Schweer, T. Krings, P. Drews, G. Offermanns, A. Pavone, J. Svensson, J. A. Alonso, R. Burhenn, R. C. Wolf, Prospects of x-ray imaging spectrometers for impurity transport: Recent results from the stellarator wendelstein 7-x (invited), Review of Scientific Instruments 89 (10) (2018) 10G101. doi:10.1063/1.5036536.

[43] A. Langenberg, J. Svensson, H. Thomsen, O. Marchuk, N. A. Pablant, R. Burhenn, R. C. Wolf, Forward Modeling of X-Ray Imaging Crystal Spectrometers Within the Minerva Bayesian Analysis Framework, Fusions Science and Technology 69 (2016) 560-567. doi:https://doi.org/10. 13182/FST15-181.

[44] K. Rahbarnia, H. Thomsen, U. Neuner, J. Schilling, J. Geiger, G. Fuchert, T. Andreeva, M. Endler, D. Hathiramani, T. Bluhm, M. Zilker, B. Carvalho, A. W. and, Diamagnetic energy measurement during the first operational phase at the wendelstein 7-x stellarator, Nuclear Fusion 58 (9) (2018) 096010. doi:10.1088/1741-4326/aacab0.

URL https://doi .org/10.1088\%2F $1741-4326 \% 2 \mathrm{Faacab0}$

[45] G. Kocsis, A. Alonso, C. Biedermann, G. Cseh, A. Dinklage, M. Jakubowski, R. König, M. Krychowiak, M. Otte, T. Sunn Pedersen, T. Szepesi, S. Zoletnik, W7-X Team, Investigation of edge filament dynamics in W7-X limiter plasmas, 43rd EPS Conf. on Plasma Physics, Leuven, Belgium 43rd.

URL

http://www. euro-fusionscipub.org/wp-content/uploads/WPS1CP16_15500_ submitted.pdf

[46] D. Carralero, P. Manz, L. Aho-Mantila, G. Birkenmeier, M. Brix, M. Groth, H. W. Müller, U. Stroth, N. Vianello, E. Wolfrum, Experimental validation of a filament transport model in turbulent magnetized plasmas, Phys. Rev. Lett. 115 (2015) 215002. doi:10.1103/PhysRevLett. 115.215002

URL https://link.aps .org/doi/10.1103/PhysRevLett.115.215002 
[47] D. Carralero, S. Artene, M. Bernert, G. Birkenmeier, M. Faitsch, P. Manz, P. de Marne, U. Stroth, M. Wischmeier, E. Wolfrum, and, On the role of filaments in perpendicular heat transport at the scrape-off layer, Nuclear Fusion 58 (9) (2018) 096015. doi:10.1088/1741-4326/aacb04. URL https : //doi .org/10.1088\%2F1741-4326\%2Faacb04

[48] L. Stephey, G. A. Wurden, O. Schmitz, H. Frerichs, F. Effenberg, C. Biedermann, J. Harris, R. Knig, P. Kornejew, M. Krychowiak, E. A. Unterberg, Spectroscopic imaging of limiter heat and particle fluxes and the resulting impurity sources during wendelstein 7-x startup plasmas, Review of

1. Scientific Instruments 87 (11) (2016) 11D606. arXiv:https://aip.scitation.org/doi/pdf/ 645 10.1063/1.4959274, doi:10.1063/1.4959274.

URL https://aip.scitation.org/doi/abs/10.1063/1.4959274 